\title{
Huaca AzNapuQuio: nuevos Datos SOBRe OCUPACIÓN HUMANA, RECURSOS HÍDRICOS Y TERRITORIO ÉTNICO EN LA CUENCA BAJA DEL CHILlóN
}

Pedro Espinoza Pajuelo* Alberto Tapia Méndez** Karen Luján Neyra***

\section{Resumen}

Además de permitirnos contar con un sustento técnico y legal para definir el área intangible del sitio, el Proyecto de Delimitación de la Huaca Aznapuquio, dirigido por el primer autor en octubre del 2006, ha generado información arqueológica para ensayar nuevas aproximaciones a los procesos sociales tardíos en el valle bajo del Chillón. En tal sentido, nuestro artículo constituye una síntesis general de los resultados del mencionado proyecto, destacando la identificación de una secuencia ocupacional interrelacionada a las fluctuaciones del humedal de Aznapuquio (actualmente desaparecido), los indicios de arquitectura con un alto nivel de elaboración y la presencia de cerámica Ichma e Inca. En base a ello, se discute las características del Horizonte Tardío en el bajo Chillón, el manejo de los recursos hídricos de la zona y los indicadores arqueológicos del territorio étnico Colli.

Palabras clave

Valle bajo del Chillón, ocupación, Horizonte Tardío, humedal, etnía, Colli, Ichma.

\begin{abstract}
The Huaca Aznapuquio Archaeological Delimitation Project, directed by the first author on October 2007, has provided legal and technical basis to protect this site and new data about the historical processes in the lower Chillon Valley during late prehispanic times. In that sense, this paper describes the general results of the project about the occupational sequence in association to the Aznapuquio wetland, the architectonical structures partially exposed for our excavations and the presence of Ichma and Inca ceramic style. Finally, we discuss about the characteristics of the Late Horizon in the valley, the water resources prehistoric management and the archaeological indicators of Colli ethnic territory.
\end{abstract}

\section{Keywords}

Lower Chillon Valley, occupation, Late Horizon, wetland, ethnos, Colli, Ichma.

\footnotetext{
* Instituto de Investigación de la Biodiversidad Naturaleza y Patrimonio Cultural - BIONAPAC. Correo electrónico: pespinoza@bionapac.org.pe,p_espinoza_p@yahoo.es.

** Instituto de Investigación de la Biodiversidad Naturaleza y Patrimonio Cultural - BIONAPAC/ Proyecto Arqueológico Los Olivos. Correo electrónico: atapia@bionapac.org.pe, tapiamendez@gmail.com. *** Instituto de Investigación de la Biodiversidad Naturaleza y Patrimonio Cultural - BIONAPAC/ Proyecto Arqueológico Los Olivos. Correo electrónico: klujan@bionapac.org.pe, arqueokaren@gmail.com.
} 


\section{INTRODUCCIÓN}

El Proyecto de delimitación de Huaca Aznapuquio, distrito de Los Olivos - Lima (Espinoza 2006), aunó a su propósito de dar un sustento técnico y legal que asegure la intangibilidad del sitio, la búsqueda de información histórica a ser difundida a la comunidad en general. Este artículo constituye un primer avance en este sentido y espera contribuir a la generación de nuevos conocimientos sobre el Chillón en tiempos prehispánicos tardíos y su relación con el fenómeno Ichma. Si bien el análisis de los materiales recuperados por nuestras excavaciones se encuentra en proceso, en este trabajo adelantaremos algunos resultados generales sobre la secuencia ocupacional del área, presentando los materiales cerámicos Ichma e Inca más representativos del sitio y que sustentan la correspondencia de éste al Horizonte Tardío. Asimismo esta secuencia ocupacional es vista aquí en correlación a las fluctuaciones del humedal de Aznapuquio y sus implicancias para el entendimiento del manejo del recurso agua en tiempos tardíos. Llama la atención que habiendo sido estos contextos tan abundantes y primordiales en el valle del Chillón, el tema del recurso agua se haya enfocado casi exclusivamente al estudio de los canales. Por último en cuanto a etnías y territorio étnico, hemos tratado de contribuir con nuevas ideas en la línea de investigación seguida por Dillehay (1976), Silva y Marcus (1988) y Silva $(1992,1996)$; procu- rando interrelacionar los datos existentes sobre las características y distribución espacial de la arquitectura y la cerámica (ante la falta de datos sobre contextos funerarios), como indicadores de territorialidad.

\section{Ubicación y descripción del sitio arqueo- lógico}

La Huaca Aznapuquio se ubica aproximadamente a $4 \mathrm{Km}$ de la ribera izquierda del río Chillón y a $7 \mathrm{Km}$ del litoral (Fig. 1). Con respecto a referencias urbanas, se halla en la Urb. Micaela Bastidas - 2o Etapa, del distrito de Los Olivos (provincia y departamento de Lima); limitando al norte con la avenida Los Alisos, al este con la avenida Las Palmeras, al sur con el pasaje Las Guirnaldas y el Instituto Educativo 2016 "Chavín de Huántar", y al oeste con el pasaje Los Helenios.

Es el único que se conserva de un grupo de cuatro montículos, casi completamente destruidos en el transcurso de las últimas décadas, caracterizados por presentar planta cuadrangular, baja altura y orientación al noreste (Fig. 2). ${ }^{1}$ En cuanto a su arquitectura, sólo se han publicado menciones generales a tapiales y "paredones" aislados que imitaban el aparejo poligonal inca (Ravines 1985: 26). Algunos muros de tapia todavía existían en el rededor inmediato de Aznapuquio hasta la década de 1990 (Manuel Guerrero, comunicación personal 2006).

Aznapuquio preserva en gran parte el vo-

1 Este conjunto ha sido denominado "Complejo Arqueológico Aznapuquio" y cada uno de sus montículos numerados de I a IV (Luján, Tapia y Ríos 2004). El designado como "Montículo I" motiva nuestro artículo. El montículo II fue arrasado hace algunos años y la zona utilizada como un parque público. El montículo III fue igualmente allanado, y el área, utilizada también como parque, se encuentra sembrada y surcada por veredas. El caso más reciente de destrucción es el del montículo IV, conocido y registrado como "Pampa de las Chivas". Este fue demolido y aplanado durante la segunda mitad de la década de 1990 para la construcción de la auxiliar de la Avenida Los Alisos, en el cruce con la Avenida Universitaria. En aquel entonces, tuvimos la oportunidad de observar los cortes sufridos por el montículo antes de ser completamente arrasado, en los cuales podía apreciarse contextos funerarios disturbados y, como única evidencia arquitectónica, bloques mampuestos de barro colocados a manera muros de contención. Actualmente es utilizada como área verde, y se han sembrado allí árboles y césped. Se constata que en las áreas verdes instaladas sobre las zonas donde se erigieron los montículos, aún pueden verse ligeras elevaciones del terreno, lo que indica que existirían evidencias arqueológicas subyacentes al nivel de la superficie actual. 
lumen que puede observarse en las fotografías aéreas de 1945, aunque su extensión ha sido recortada por la construcción de la avenida Las Palmeras y más recientemente, en el año 2004, por la auxiliar de la avenida Los Alisos a la altura del cruce con la primera avenida mencionada. El montículo alcanza hasta $5 \mathrm{~m}$. de altura, mientras que sus lados tienen una longitud máxima de $80 \mathrm{~m}$. en dirección noreste a suroeste por $65 \mathrm{~m}$. de noroeste a sureste.

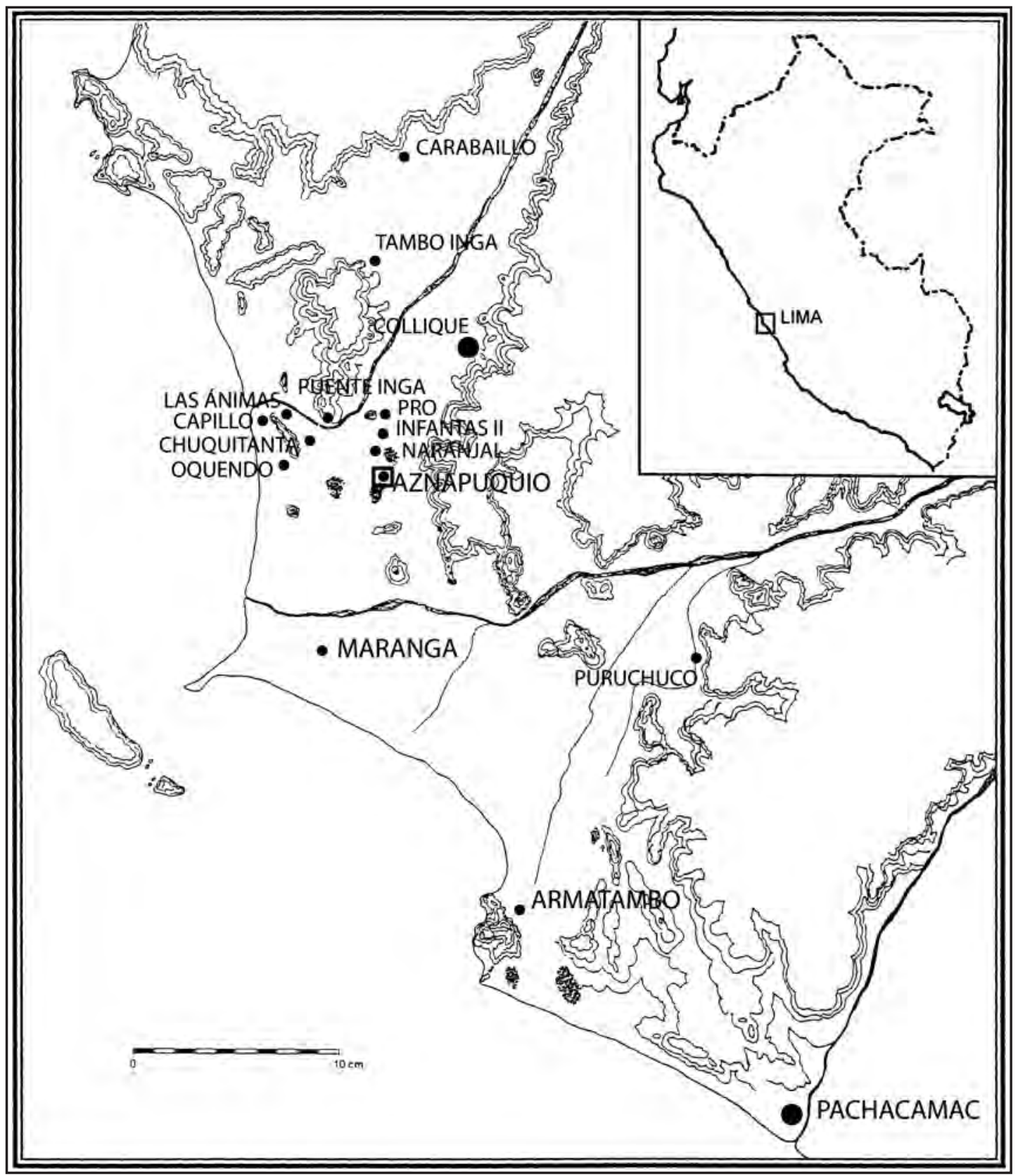

Figura 1. Ubicación de Aznapuquio y otros sitios tardíos relevantes de la Costa Central Peruana

(en base a Tello 1999: 53). 







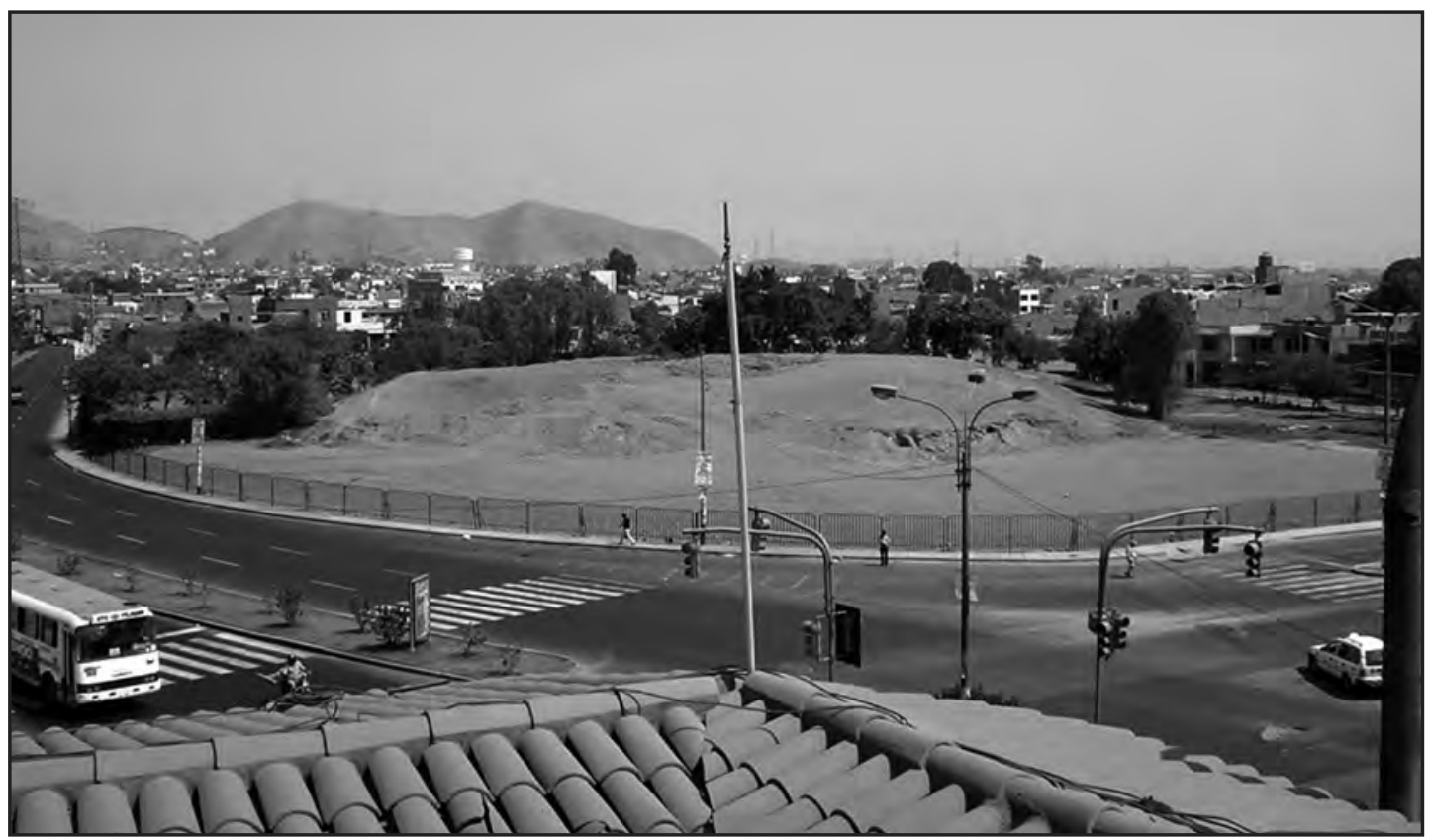

Figura 3.- Vista general de Huaca Aznapuquio desde el noroeste, a la altura del cruce de las avenidas Las Palmeras y Los Alisos.

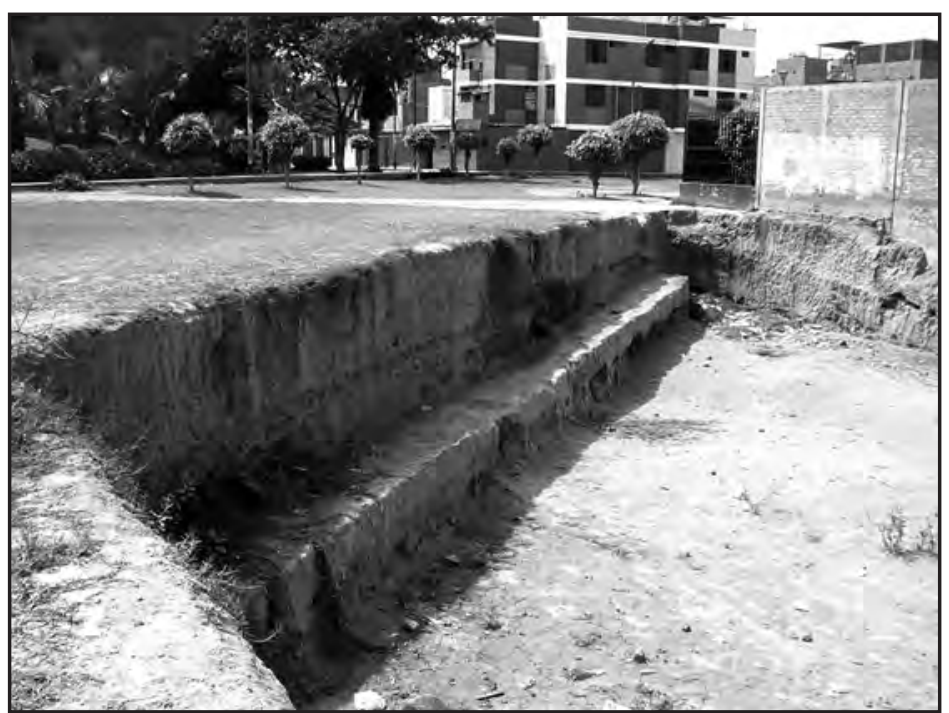

Figura 4.- Vista general del corte 1 en relación a las construcciones modernas del entorno. Los árboles del extremo superior izquierdo rodean la parte sur del montículo arqueológico. El enrejado y la pared parcialmente blanqueada que se observan a la derecha pertenecen al Instituto Educativo "Chavín de Huántar".

Pueden verse huellas de palas mecánicas que han cercenado su lado noroeste, de tal forma que allí han quedado expuestos restos de muros, rellenos y pisos. Como veremos, estas evidencias arquitectónicas han sido registradas como parte de nuestra unidad de excavación. Aparte de ello, no se observan más estructuras en superficie ni se disciernen plataformas que configuren los flancos del montículo (Fig 3).

Por otra parte, a $30 \mathrm{~m}$. al suroeste el terreno muestra un marcado talud que desciende hacia una amplia depresión delimitada por las avenidas Alisos al norte; Universitaria al oeste y el Psje. Los Helenios al este; siendo indeterminada su extensión hacia el sur. Esta depresión corresponde al lecho de un antiguo humedal (Cerdán y Pontero 1965 [1793], citado por Domínguez 1988; Ludeña 1975, Ravines 1985, Paredes 2000), hoy completa- 
mente desecado y ocupado por urbanizaciones. A la altura del borde oeste de la cuadra 2 de Los Helenios, encontramos que el talud había sido cortado verticalmente (aunque el desmonte que debió obtenerse de ello ya había sido completamente retirado), con el fin emplazar construcciones modernas en la parte baja de éste. Esta labor dejó expuesto un perfil del que se registraron dos zonas expuestas, en las que se aprecian capas con material cultural prehispánico, correspondientes a estratos de basura. La primera de estas zonas fue denominada "Corte 1" y se ubica de manera adyacente al frontis Norte del Instituto Educativo "Chavín de Huántar" (Fig. 4 y 5 , a). La segunda de éstas, designada como "Corte 2" (Fig. 5, b), está ubicada del otro lado del frontis de dicho instituto y bajo una vía de circulación pública. El Corte 1 es escalonado y está abierto hacia el oeste. Tiene una profundidad total de $5.13 \mathrm{~m}$ por una longitud de $26 \mathrm{~m}$ en su perfil norte y $24 \mathrm{~m}$ en su perfil noreste; y permanece visible hasta la fecha de preparación del presente artículo. Por otra parte, el Corte 2 estaba abierto hacia el Oeste, aunque se hallaba rodeado por viviendas. Su profundidad total era de $4.23 \mathrm{~m}$ por $4 \mathrm{~m}$ de longitud en su perfil norte y $7.79 \mathrm{~m}$ en el este. En su extremo sur el perfil doblaba al oeste, formando una esquina, y luego proseguía hacia el sur prolongándose 25 $\mathrm{m}$. El corte fue cubierto, pocos días después de iniciado nuestro trabajo de campo, por un muro de contención de piedras y concreto, construido como parte de obras municipales para pavimentación de la cuadra mencionada. Más adelante explicaremos cómo estos cortes nos han servido a manera de una columna estratigráfica maestra para el área evaluada.

Finalmente, en los primeros días de nuestro proyecto recuperamos material cerámico remo- vido y se registró la estratigrafía de una zanja (Fig. 5 , c) de $1 \mathrm{~m}$ de profundidad y $0.6 \mathrm{~m}$ de ancho, abierta para obras municipales en la berma central de la avenida Los Alisos, frente a nuestra zona de trabajo.

\section{Antecedentes de investigación y problemática}

A excepción de la tesis doctoral de Hugo Ludeña (1975), Aznapuquio sólo cuenta con antecedentes de investigación sumamente generales. Haremos mención a ellos según las temáticas de ocupación, recursos hídricos y corología que guían nuestro presente estudio.

\subsection{Ocupación}

En el contexto ocupacional tardío de la cuenca baja del Chillón, comprendida entre el litoral y la localidad de Huanchipuquio, el sitio arqueológico de Aznapuquio se asociaba a una red de caminos en uso durante el Horizonte Tardío y que lo interconectaban directamente con asentamientos que habrían sido estratégicos para la distribución económica durante dicho periodo. Julio C. Tello (1999: 53) grafica a grosso modo una ruta que unía Pachacamac y Ancón, pasando por las inmediaciones de nuestro sitio y prolongándose hasta Puente Inca y Tambo Inca, pertenecientes ambos al Horizonte Tardío (Bonavia 1966: 35, Ludeña 1975: 66, Silva 1992: 398). Es evidente la importancia de los asentamientos en Puente Inca ${ }^{2}$ para el control de la circulación entre ambas riberas del Chillón; mientras que, por su toponimia, Tambo Inca ha sido caracterizado como un centro de acopio y almacenamiento (Villar Córdova 1982: 169). Valga acotar que desde el sector "A" de Puente Inca, en la margen izquierda del Chillón, parte al oeste un camino amurallado (es decir, delimitado por muros de tapia paralelos) que se dirige

2 A cada lado del puente que da nombre al sitio se halla un asentamiento prehispánico tardío. Silva denomina Puente Inca a aquel conocido como Cerro Respiro, ubicado en la margen derecha. No obstante, debe distinguirse este del ubicado en la margen opuesta y registrado por el INC como "Sector A de Puente Inca". En el presente artículo mantendremos la denominación Cerro Respiro para el primero y Sector "A" de Puente Inca para el segundo. 


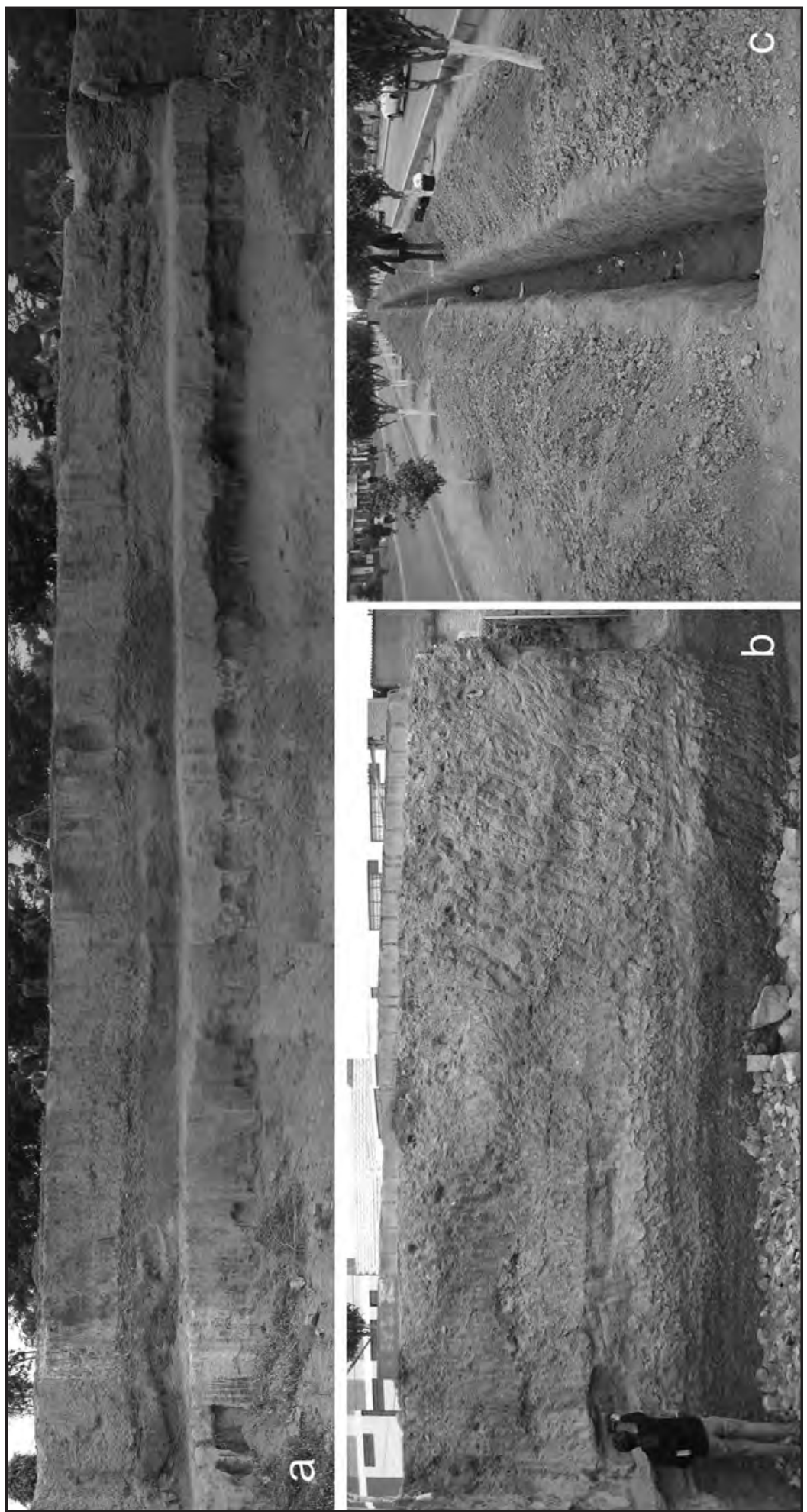

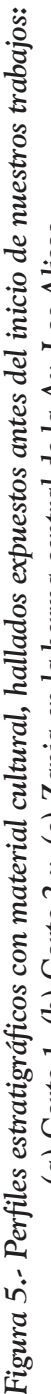


hacia Chuquitanta y el "Palacio de Oquendo", este último también de la época Inca (ver sitio PV46-553 en Silva 1992: 398). De igual forma, aparentemente a la altura de Macatampu, en el bajo Rímac, se iniciaba un camino también de tipo amurallado, el cual constituía un ramal de aquél que pasaba por Aznapuquio. ${ }^{3}$ Este ramal subía por la banda izquierda del Chillón, alcanzando la fortaleza de Collique, y llegaba hasta Trapiche, donde cruzaba el río (Villar Córdova 1982: 190). No hay indicios de alguna ruta directa que una Aznapuquio con Chuquitanta o con Collique, dos sitios que, como veremos, han sido adscritos por diversos investigadores al Señorío de Colli durante el Intermedio Tardío.

Se debe a Hugo Ludeña (1975), las únicas referencias específicas sobre ocupación en Aznapuquio. Dicho investigador registra la presencia de cerámica de estilo Inka, coloraciones rojizas en el suelo que evidenciarían hornos para cerámica y desechos de cocción (tales como abundante fragmentería con tiestos recocidos). Ludeña acota que la cerámica de Aznapuquio tiene formas idénticas a las de Collique, lo que le lleva a afirmar que "es altamente probable que en Aznapuquio estuviera ubicado un centro de producción de cerámica inca para el valle" (Ludeña, 1975: 45, 47).

\subsection{Recursos hídricos}

Existen referencias a una "laguna" o humedal, hoy desaparecido, en cuyas orillas se disponían los montículos del Complejo Arqueológico Aznapuquio. Uno de los registros más tempranos de este humedal proviene de Cerdán y Pon- tero (ver plano 4 de Domínguez 1988, basado en Cerdán 1965[1793], y Gunther 1983). En tal sentido, "Aznapuquio", denominación quechua que se traduce como puquio maloliente, era conocido en la Colonia y se dice que los virreyes iban allí a cazar aves (Ludeña, 1975: 44). Sin embargo, es calificado sólo como un estanque por Roger Ravines (1985: 26) o un humedal de menor importancia por Juan Paredes (2000: 134). Cabe resaltar que Ravines alude a un sistema de riego que habría vinculado al sitio con los conjuntos arqueológicos de Santa Rosa y Naranjal (Íbíd.).

\subsection{Territorio étnico}

El Complejo Arqueológico Aznapuquio se hallaría dentro del territorio del Señorío de Colli, tal como este es definido por María Rostworoski, es decir desde el mar hasta más arriba de Quivi, en Chuquicoto, donde el cerro Judcunga separaba a los Collis de los Canta, con quienes se encontraban en constantes luchas (Rostworoski 2004: 28 y 30). A dicho señorío se adscribían una serie de curacazgos menores como Collec, Chuquitanta, Seuillay, Comas, Sutca y Carabayllo en el valle bajo; Sapan, Guancayo y Quibi en la margen izquierda de la cuenca media; y Macas, Guarauni y Missai en la margen opuesta de la misma sección del valle (Rostoworowski 2004: 296). De esta forma, los colli habrían conformado una extensa macroetnía preincaica que en determinado momento habría llegado a ocupar parte del valle de Lima (Íbid, también en 2004: 31), ${ }^{4}$ pero que al resistir a la invasión de Túpac Yupanqui, fueron derrotados, siendo

3 Decimos que el camino se bifurca aparentemente en Macatampu ("Makat") pues es confusa la descripción que Villar Córdova (1982: 190) hace del tramo Macas - Pachacamac, el cual pasaba por aquel desaparecido sitio arqueológico.

4 En el documento de Huarochirí (Avila 1966 [1598]: passim), se señala que los pueblos yauyos de Llacsatambo, Yarutini y Colli (este último en territorio Checa) estuvieron originalmente ocupados por yungas collis, los que fueron luego desalojados y forzados a volver a la costa. Sorprende la mención a poblaciones colli tan alejadas del bajo Chillón, aunque resultaría especulativo calificarlas sólo por ello como enclaves económicos. Carahuayllo, como lugar y etnía, es también mencionado en este mismo documento, indicándose que Collis y Carahuayllos asistía en peregrinación a la fiesta de Pariacaca (Ibid: 69). 
reemplazado su gobernante nativo por un yanacona designado por el Inca. Aunque los colli del virreynato se hallaban sumamente diezmados, el testamento de su curaca don Francisco Yauyi, de 1564, señala algunas propiedades que podrían servir de referencia para trazar la extensión del señorío por el norte y sur: en la margen izquierda desde Comas, Collique, y Con - con hasta Punchauca y Huacoy, y en la margen opuesta, parte del valle de Carabayllo hacia los cerros de Lomas, la Ysleta y Omas (Rostworowski 2004: 39). La visita de Martínez de Rengifo de 1571 da una idea de las etnías de Colli, mencionándose diez pachacas de las cuales la única que nos resulta familiar como toponimia, es Chuquitanta. Hacia 1784 un censo sobre provincias de la Intendencia de Lima menciona aún a las etnías Chuquitanta, Comas y Carabayllo, Guancayo y Collique (Íbid: $44-45$ ).

Por su parte, la arqueología ha buscado correlacionar las evidencias materiales con la información etnohistórica. Para el caso del bajo Chillón, zona en la que centraremos nuestra discusión, Tom Dillehay (1976: 202) vincula el sitio de Carabayllo al curacazgo del mismo nombre y Jorge Silva (1996: 195) hace lo propio con lo que denomina "Complejo Chuquitanta"; mientras que ambos coinciden en caracterizar al sitio de Cerro Collique como el centro principal del señorío epónimo. Estos acercamientos están mayormente basados en la constatación de concentraciones de sitios arqueológicos en zonas con toponimias conocidas de acuerdo a los documentos coloniales. Por su parte, Miguel Cornejo (1999: 204 - 206) considera que el sitio de Aznapuquio se asociaría al valle del Rímac como parte de lo que él ha denominado "Curacazgo de Aznapuquio", donde incluye una treintena de sitios en los distritos de Los Olivos, San Martín de Porres, Independencia y parte del Rímac. Según Cornejo, esta extensa área está irrigada por el canal de Piedra Lisa, cuya bocatoma está en la base del Cerro San Cristóbal y por los manantiales de Bocanegra y Aznapuquio.

Sin embargo, la formulación de indicadores arqueológicos como la cerámica para definir entidades sociopolíticas es problemática y aparece fundamentalmente como demasiado general. A nuestro parecer ello se debe no sólo a las limitaciones intrínsecas de los indicadores de etnicidad, ${ }^{5}$ sino a que dicha formulación ha aparecido subsumida a la necesidad de definir arqueológicamente a las "Provincias", "Señoríos" o "Curacazgos" que se mencionan en la documentación colonial, con el consecuente peligro de caer en una argumentación tautológica que pretende desarrollar una demostración de algo que ya se da por sentado (Kaulicke 2004: 340). Igualmente, si bien han comenzado a haber ensayos de caracterización arqueológica de estos conceptos (Cornejo 2000, Astuhuamán 2006), tales intentos aparecen restringidos a la época Inca. Surge entonces la pregunta de cómo funcionaron originalmente las organizaciones completamente modificadas por la presencia cusqueña, hasta el punto que prácticamente no sobrevivieron a la Colonia (como, justamente, es el caso de los Colli). Para el caso, valga recordar que los Inca hacen cambios sustantivos en las estructuras locales movilizándolas, reorganizándolas o aún aniquilándolas cuando se les oponían férreamente, como en el caso de los Quibi (Rostworowski 2004: 35).

\section{Unidades de excavación y registro de cor- tes expuestos.}

Las investigaciones del Proyecto de Delimitación de Huaca Aznapuquio se sustentaron en que el monumento no contaba con un expediente técnico de delimitación aprobado y formalmente reconocido, por lo que en el marco del Proyecto "Fortalecimiento de la Identidad" de la Municipalidad de Los Olivos, se realiza-

5 Para una discusión sobre indicadores arqueológicos de etnicidad véase Kaulicke (2004). 
ron excavaciones con este fin. Sin embargo, y más allá de su fin estrictamente técnico, nuestro proyecto buscó recuperar información histórica que pudiera ser difundida a la comunidad. Con estos objetivos en mente, se abrieron un total de 15 Unidades de Excavación de $2 \times 2$ m, orientadas al norte (a excepción de la unidad 14) y numeradas de acuerdo a su orden de apertura

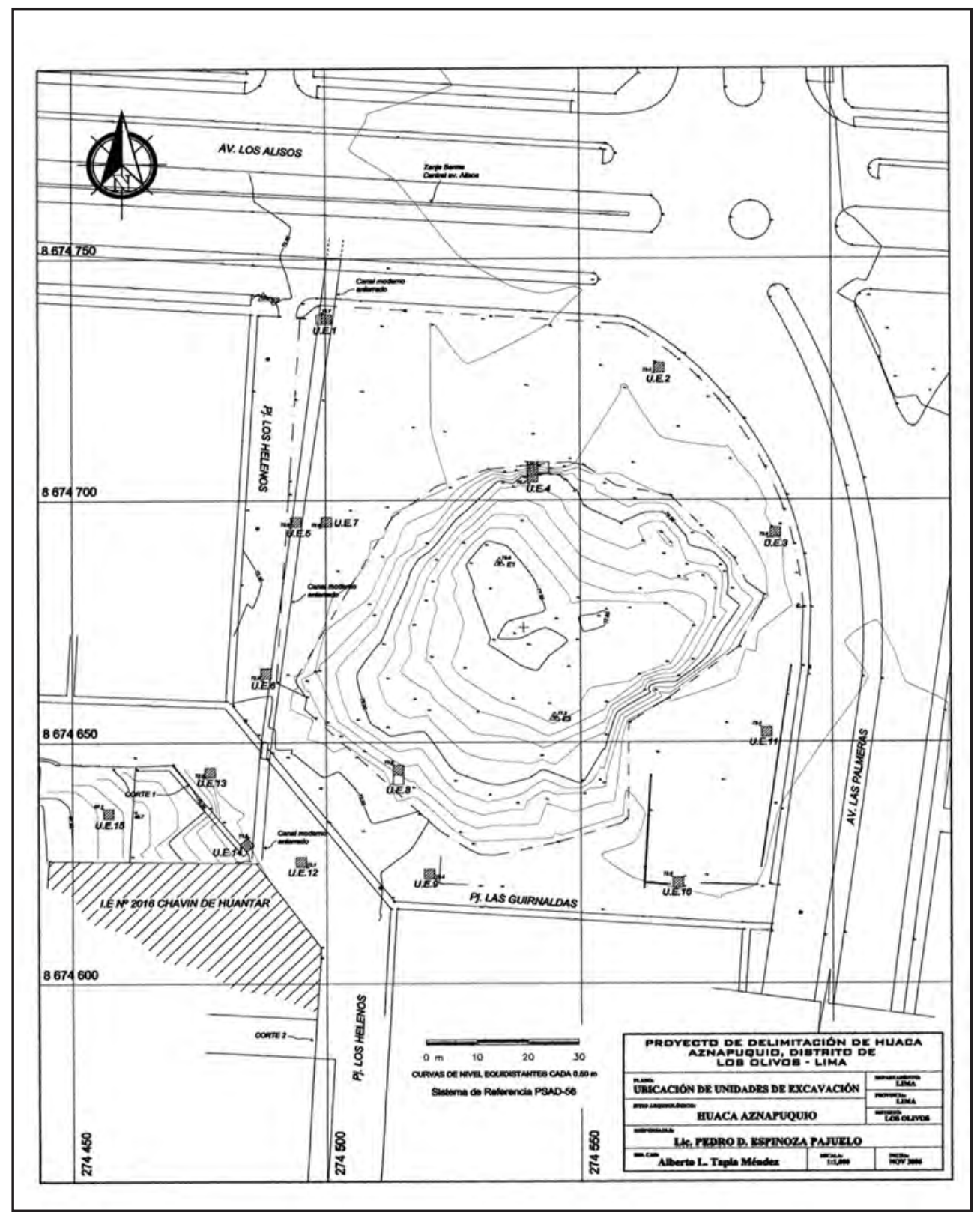

Figura 6. Plano General de Aznapuquio, con indicación de las unidades de excavación. 
(Fig. 6). Once de ellas se excavaron en el terreno llano que circunda el montículo, con el fin de determinar su área intangible. Otras dos, las unidades 4 y 8 , se abrieron en la base del mismo, para correlacionar la estratigrafía obtenida allí con aquella de las unidades periféricas y poder definir así sobre qué capa fue construido. Así también, estas dos unidades nos permitieron registrar elementos arquitectónicos expuestos en el corte del lado noroeste del montículo, que mencionáramos páginas atrás. Por otra parte, la unidad 14 se excavó en forma adyacente al borde del Corte 1, para recuperar controladamente material cultural en contexto del basural expuesto allí. Por este motivo tuvo una orientación al noroeste. La unidad 15 se emplazó a 46 $\mathrm{m}$. al suroeste del montículo, en un terreno libre ubicado en la parte más profunda del relieve actual y destinado para la construcción de un local Comunal del Asentamiento Humano "12 de Octubre". Tuvo la finalidad de complementar nuestra secuencia estratigráfica determinando evidencias culturales previas a la existencia del humedal y que por ende serían más antiguas a las identificadas en el entorno inmediato de la Huaca Aznapuquio y en el Corte 1.

Por otra parte, la considerable profundidad y amplitud de los cortes 1 y 2 (el primero de ellos, especialmente) nos sirvió para tener una columna estratigráfica que podía ser contrastada con la que se iba obteniendo en las unidades de excavación. Igualmente pudimos ver cuáles eran las capas asociadas a los niveles de ocupación y hasta qué profundidad podían ser halladas evidencias culturales, gracias a que la estratificación en el área es bastante homogénea. El material cultural (fragmentos de cerámica) asociado al Corte 1 pudo ser colectado, como explicáramos, a través de la Unidad 14. Del Corte 2, se recuperó tanto material disperso en la base de éste como aquél que estaban desprendiéndose de los perfiles, consignándose en este último caso la capa a la que se asociaban.
Así mismo la zanja en la berma central de la avenida Los Alisos fue registrada en forma fotográfica y descriptiva, colectándose el material cerámico que se observaba en el desmonte.

\section{Resultados}

\section{4,1. Ocupación}

Las excavaciones demuestran un patrón deposicional bastante homogéneo en toda el área intervenida por nuestra excavaciones, de tal manera que es posible identificar ciertos estratos sedimentarios, originados por variaciones en el aforo hídrico del humedal a través del tiempo, que se extienden por toda esta posibilitando ordenar la secuencia de ocupaciones en relación a este proceso (Figs. 7 y 8).

Las evidencias más antiguas son de carácter aislado y poco definido cronológicamente. Las más profundas de la secuencia (posición estratigráfica "7" en la Fig. 8) fueron halladas en la Unidad 15, las cuales consisten en un delgado lente de ceniza con algunos fragmentos muy pequeños de restos malacológicos. Sin embargo su cronología es indeterminada debido a la ausencia de material cultural diagnóstico. Al crecer el humedal, estas evidencias son cubiertas por sedimentos estériles de origen hídrico, constituidos mayormente por arcilla y arena, y que suman hasta $1.7 \mathrm{~m}$ de espesor. Entre éstos se deposita una capa de arena conteniendo material cerámico disperso (capa 7 del Corte 1, Fig. 9, y posición estratigráfica "6b" en la Fig. 8), no diagnóstico. Otros restos tempranos están representados por el material asociado a un lente de arena entremezclada con concreciones de carbonato de calcio ("caliche") en el Corte 2 , entre los cuales se recuperó un fragmento de cántaro con decoración estampada de puntos en relieve (Figs. 10 y 11). Dicho lente tiene una posición estratigráfica poco más superficial que la capa 7 del corte 1 , por lo que referencialmente se le consigna en la Fig. 8 como "6a". Ambas acumulaciones representan actividades de 




Figura 7. Matriz de Harris con las correlaciones estratigráficas entre las diversas excavaciones y cortes expuestos (Z1: zanja en la berma central, U: unidad de excavación, C1: corte 1, C2: corte 2).

descarte (acumulación de basura) en las orillas del humedal, las cuales podrían remontarse a la época 3 o 4 del Horizonte Medio (Menzel 1968: 196, Ravines 1981: 163, Kaulicke 1997: Fig. 60, 10). ${ }^{6}$ Sin embargo nos hace falta complementar el análisis de los materiales cerámicos para definirlo con certeza.
Estos niveles de ocupación son cubiertos por sedimentos arenosos estériles que indican una nueva expansión del humedal, y a los que se superpone una capa de arena arcillosa de color crema, homogénea en toda el área. En las cortes 1 y 2 , y en las unidades de excavación 13 y 14 , se ha determinado que sobre esta capa

6 Ravines publica información sobre un contexto funerario de Ancón en el que se aprecia que la cerámica moldeada antropomorfa, atribuida por Menzel a la época 3 del Horizonte Medio, se asocia a una vasija con decoración de puntos en relieve como los de Aznapuquio (Ravines 1981: 134, sp. 9242). Un cántaro con una decoración similar es adscrito por Kaulicke probablemente al Horizonte Medio 4. Aún no se han realizado estudios sobre la pervivencia de este tipo de decoración hasta el Horizonte Tardío en la Costa Central. 


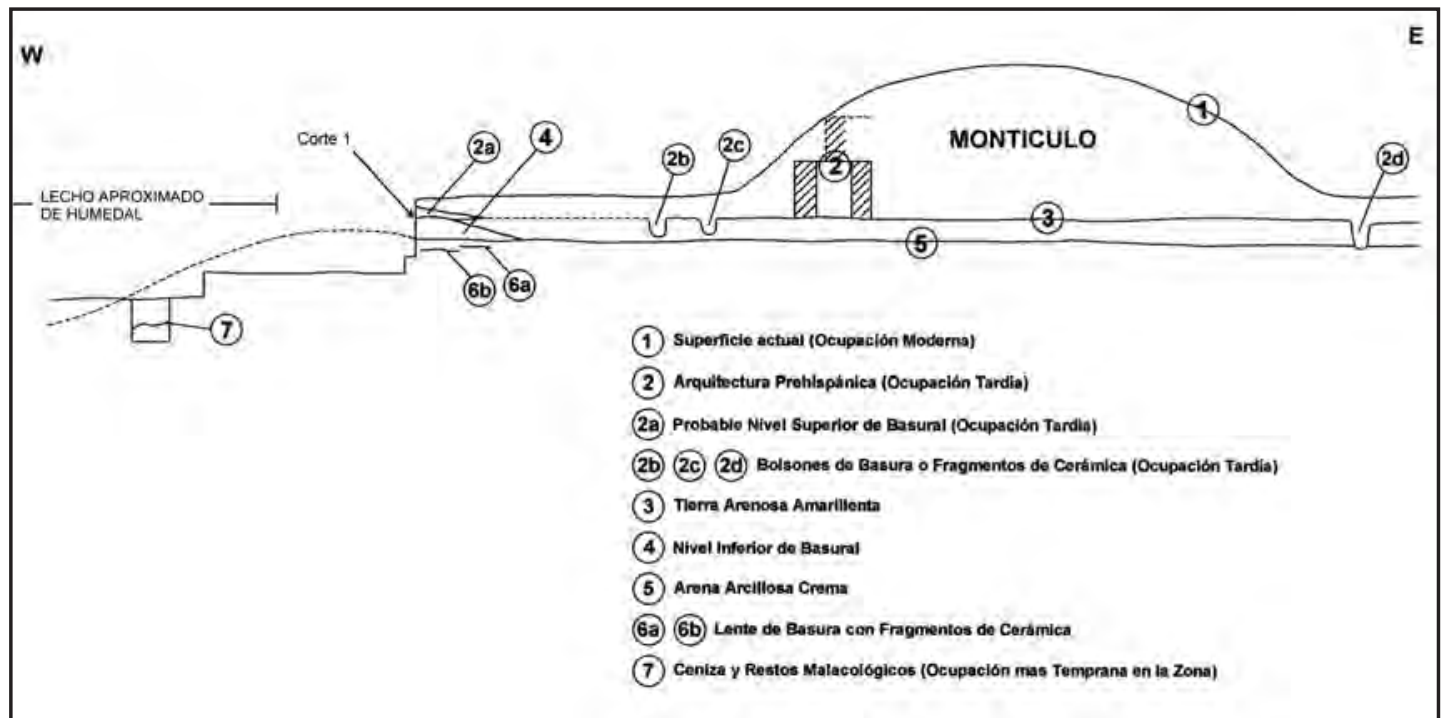

Figura 8. Corte esquemático del área de Aznapuquio, indicando la ubicación estratigráfica relativa de las evidencias ocupacionales y el lecho aproximado del humedal en su momento de asociación al nivel inferior del basural.

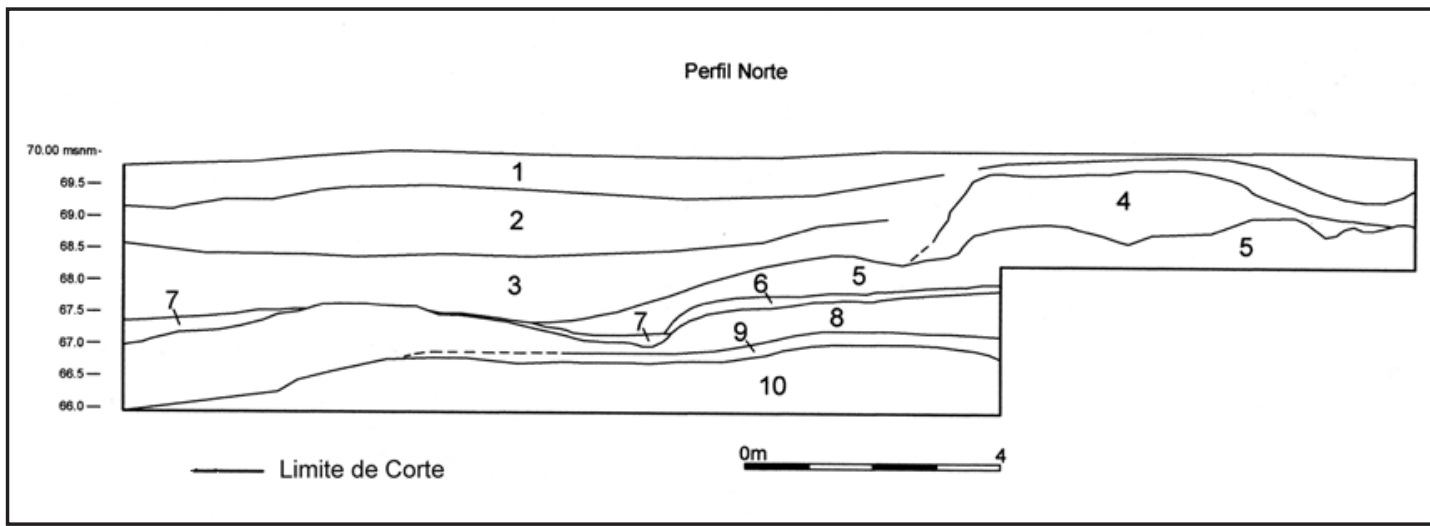

Figura 9.- Perfil norte del Corte 1. En la capa 7 se halló cerámica no diagnóstica dispersa. El contorno de la capas 5 y 7 constituiría parte del lecho del humedal, que se profundiza hacia el oeste. La capa 4, corresponde a acumulaciones de basura arqueológica.

aparece una densa y extensa acumulación de materiales arqueológicos entre los que se observan (en orden de preponderancia) fragmentos de cerámica, restos óseos animales, restos malacológicos, núcleos y lascas. Esta acumulación constituye los remanentes de un basural tardío que debió extenderse en las orillas del humedal. En este momento es posible además delinear el relieve que tuvo el mencionado humedal (Figs. 8 y 9). Ahora bien, hemos apreciado que existen en realidad varios lentes de acumulación de basura separados por capas de arena de aparente origen antrópico. El más temprano de estos (“4” en la Fig. 8) sería previo a la construcción de arquitectura en el sitio, mientras que alguno o varios de los siguientes ("2 a" en la Fig. 8) muy probablemente serían contemporáneos a esta, ya que de acuerdo a la cerámica revisada todos ellos corresponden al Horizonte Tardío (Fig.20, b). Para el caso, no es posible establecer una separación estratigráfica evidente entre ambos momentos del basural, ya que la capa de arcilla 


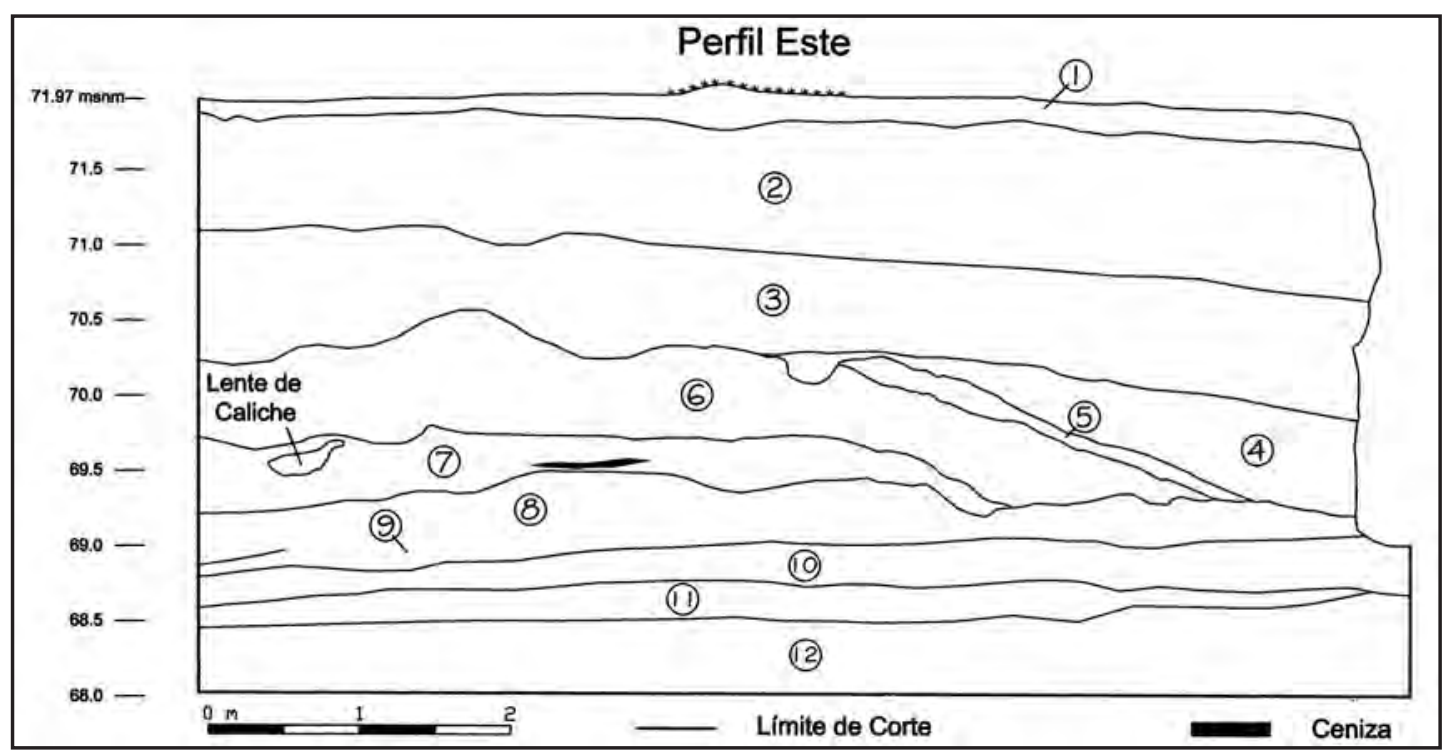

Figura 10.- Perfil este del Corte 2.

amarillenta ("3" en la Fig. 8), asociada a la arquitectura del sitio, no se prolonga claramente hasta aquel.

La capa de arcilla amarillenta que acabamos de mencionar, y que se ha podido detectar en toda el área, señala el inicio de la ocupación intensiva de Aznapuquio. En asociación a esta se erige la arquitectura que hemos identificado en el montículo ("2" en la Fig, 8) y se presentan bolsones de fragmentos de cerámica además de acumulaciones de tiestos que hemos registrado en la zanja de la berma central de Los Alisos ("2b", "2c" y "2d" en la Fig. 8). Es esta masiva ocupación la que ha recibido la atención de los investigadores (Ludeña 1975, Cornejo et al. 2005) y para la que podemos corroborar una filiación al Horizonte Tardío, tal como se expresa en la presencia de formas Ichma e Inca cuzqueño (Figs. 12, a y b; 13, a y b; 14,15 y 16) ${ }^{7}$, aunque material de este último estilo se ha recuperado sólo en superficie. En tal sentido, consideramos que el principal aporte de nuestras excavaciones es que tenemos indicios de que el sitio habría cumplido funciones que van más allá de la simple producción cerámica que le señaló Ludeña. Es así que destacaremos que las estructuras que hemos descubierto en nuestras unidades 4 (Fig. 17) y 8 (Figs. 21 y 22), muestran un cuidadoso

7 Compárese nuestra figura 12, a; con la figura 16,c, (Ychsma Tardío A) publicada en Vallejo 2004. Esta forma guarda estrechas similitudes con el grupo "W" de Dillehay (1976: 157), quien lo considera frecuente en el alto Chillón (Arahuay) entre el Horizonte Medio y el Horizonte Tardío. Para la figura 12, b; véase Vallejo 2004: Fig. 8, j (Ychsma Medio A). Referencias a la forma de la Fig. 12, c; pueden revisarse en Vallejo 2004: 622, que la atribuye a su fase Ychsma Tardío A. También es recurrente en Huaca San Miguel de Maranga (Carrión y Espinoza 2007b: Figura 14). El fragmento superior derecho de la Fig. 16 pertenece a una olla con asa cintada que une el labio y el hombro de la vasija, típica de la fase Ichma Tardío B (Vallejo 1998, véase también Carrión y Espinoza 2007a: Figura $7,18)$. Se comprueba que estas formas Ichma Medio A e Ichma Tardío A se mantienen hasta época Inca, cuando se da la ocupación intensiva de Aznapuquio. Al respecto, Feltham y Eeckhout (2004: 673) señalan que un 60\% de tipos y subtipos Ichma del Intermedio Tardío, definidos en la pirámide III de Pachacamac, siguen siendo producidos en el incanato. 


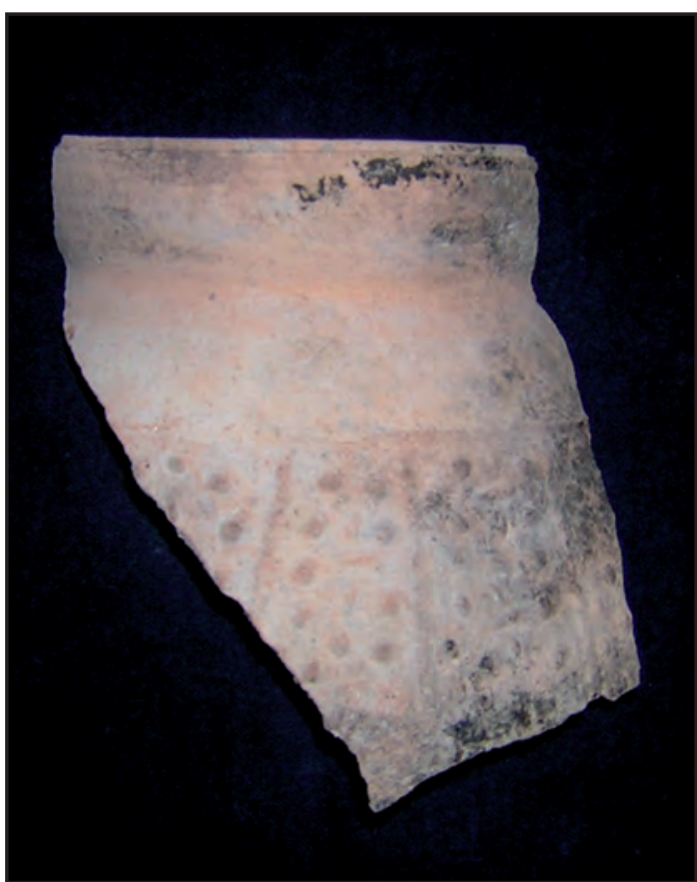

Figura 11.- Cerámica estilo Pativilca, recuperada de un lente de caliche en el Corte 2.

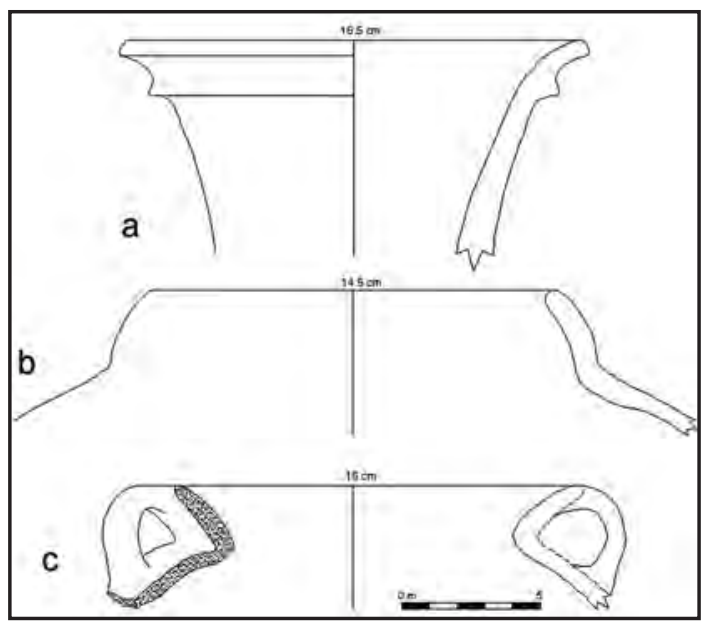

Figura 12.- Material cerámico de Aznapuquio: (a) cántaro de cuello cóncavo-divergente y borde con bisel externo y cornisa, (b) Olla de cuello corto convexoconvergente, y (C) Olla con borde recto divergente y asas lateral que unen labio y hombros.

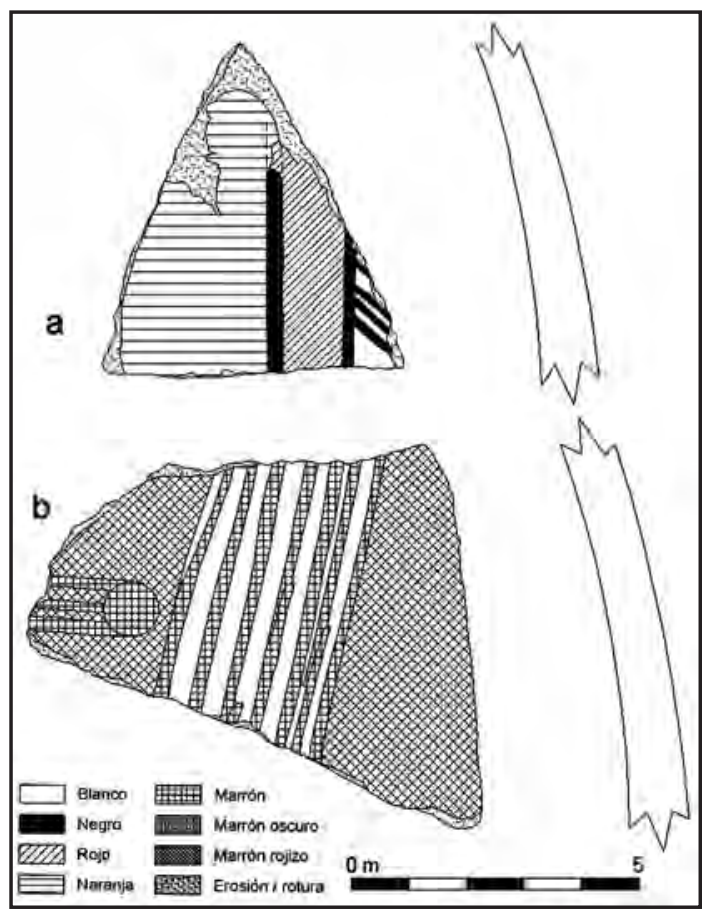

Figura 13.- Material cerámico de Aznapuquio, procedente de superficie: (a) y (b) fragmentos decorados de aríbalos.

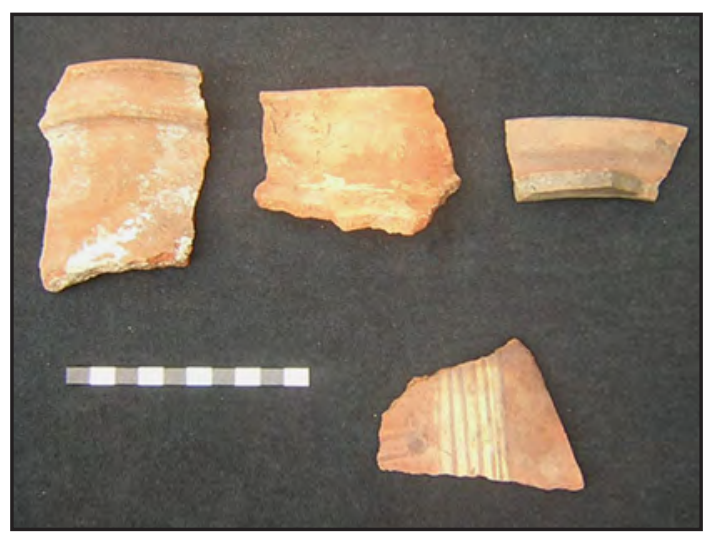

Figura 14.- Material cerámico de Aznapuquio, procedente de superficie. Destacan un fragmento de labio con reborde y bisel externo (extremo superior izquierdo

-Fig. 12, a) y un fragmento con motivos listados característicos de los aríbalos inca (fragmento inferior -también Fig. 13, b). 


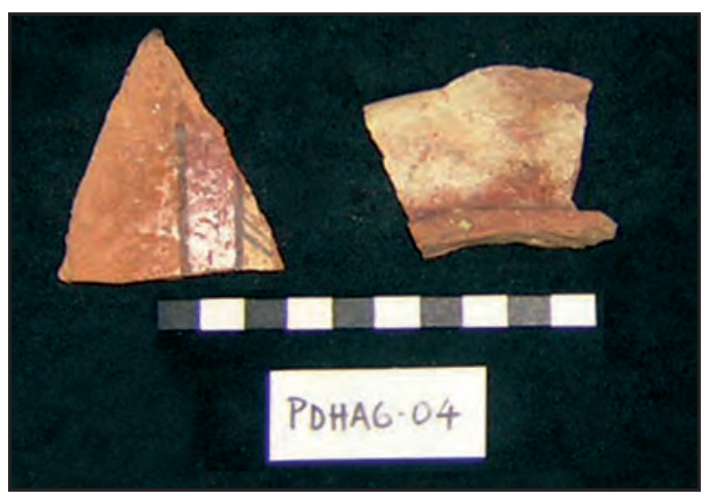

Figura 15.- Material cerámico de Aznapuquio, procedentes de superficie de la capa 4: (a) fragmento de aríbalo decorado con el motivo del "helecho" (ver Fig. 13, a) y (b) olla de cuello recto divergente.

tratamiento y mantenimiento, enmarcados en una actividad constructiva en el que se manifiestan varios momentos.

Es así que en la unidad 4, se registraron un total de 21 estratos (entre pisos, rellenos cons- tructivos y deposiciones naturales) y cinco muros de tapia, cuyas asociaciones evidencian siete momentos constructivos, cada uno de ellos con diversas remodelaciones (véase Fig. 18). El primer momento correspondería a la construcción del piso (capa 16) sobre el que se construye el Muro 4, delimitándose así un amplia área libre. En el segundo momento, el Muro 4 continua siendo utilizado, el área libre es rellenada (capa 14) y sellada con un nuevo piso (capa 13) sobre el que se construye el Muro 3. La disposición de ambos muros nos hace pensar que inicialmente el Muro 4 debió haber funcionado solo con el piso, posteriormente se habría añadido el Muro 3. En el momento siguiente, éste ambiente es rellenado (con las capas 11 y 12) y sellado por un piso (capa 10), sobre el cual se construyen hasta seis nuevos pisos y/o remodelaciones (capa 9), en donde el penúltimo parece haber sido escenario de una amplia y prolongada que-

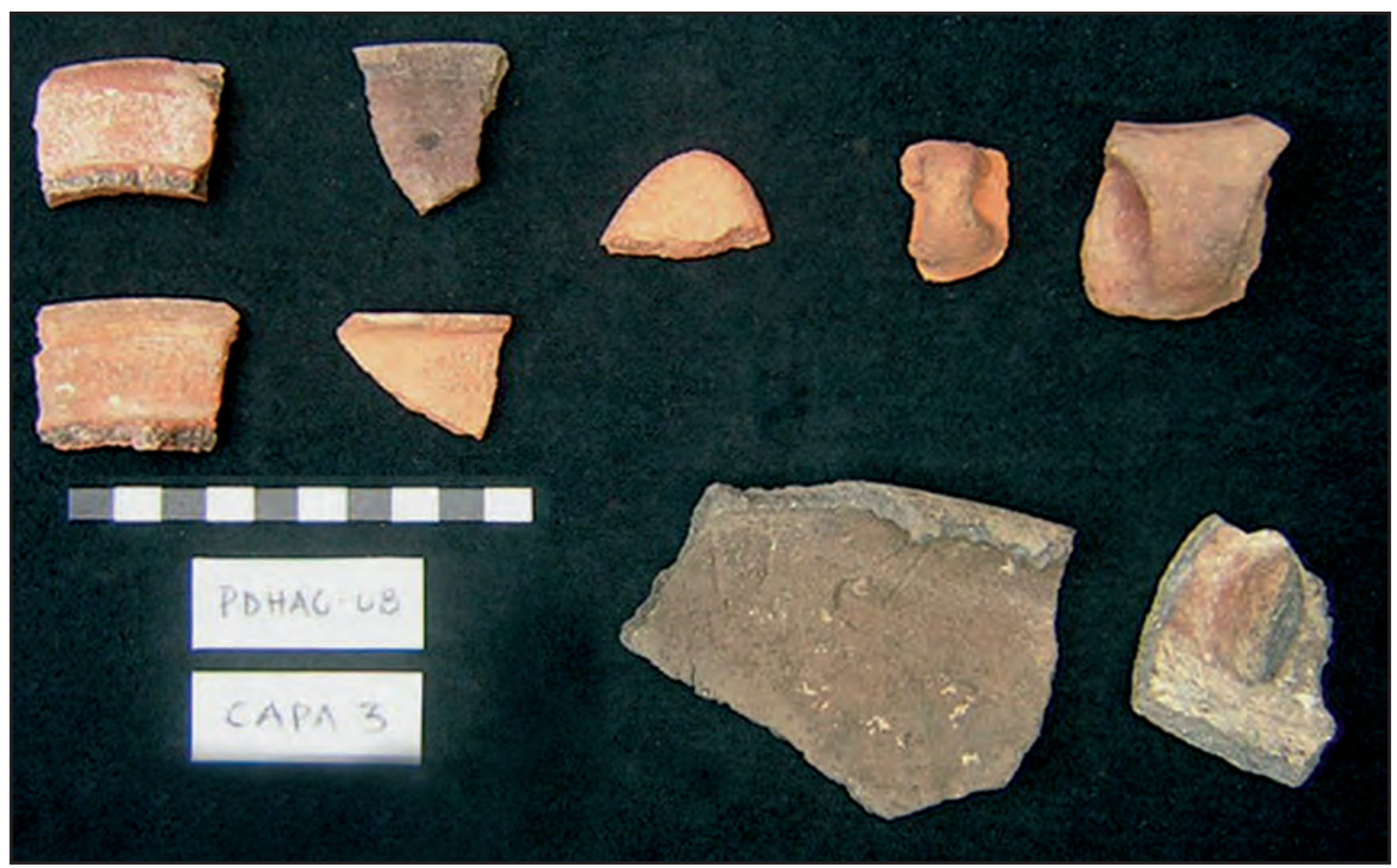

Figura 16.- Material cerámico de Aznapuquio, de la capa 3 de la unidad 8: se aprecian el borde de una tinaja con borde en " $T$ " (extremo superior izquierdo), fragmentos de platos (extremo superior derecho) y cerámica deformada por sobre cocción (fila inferior). 


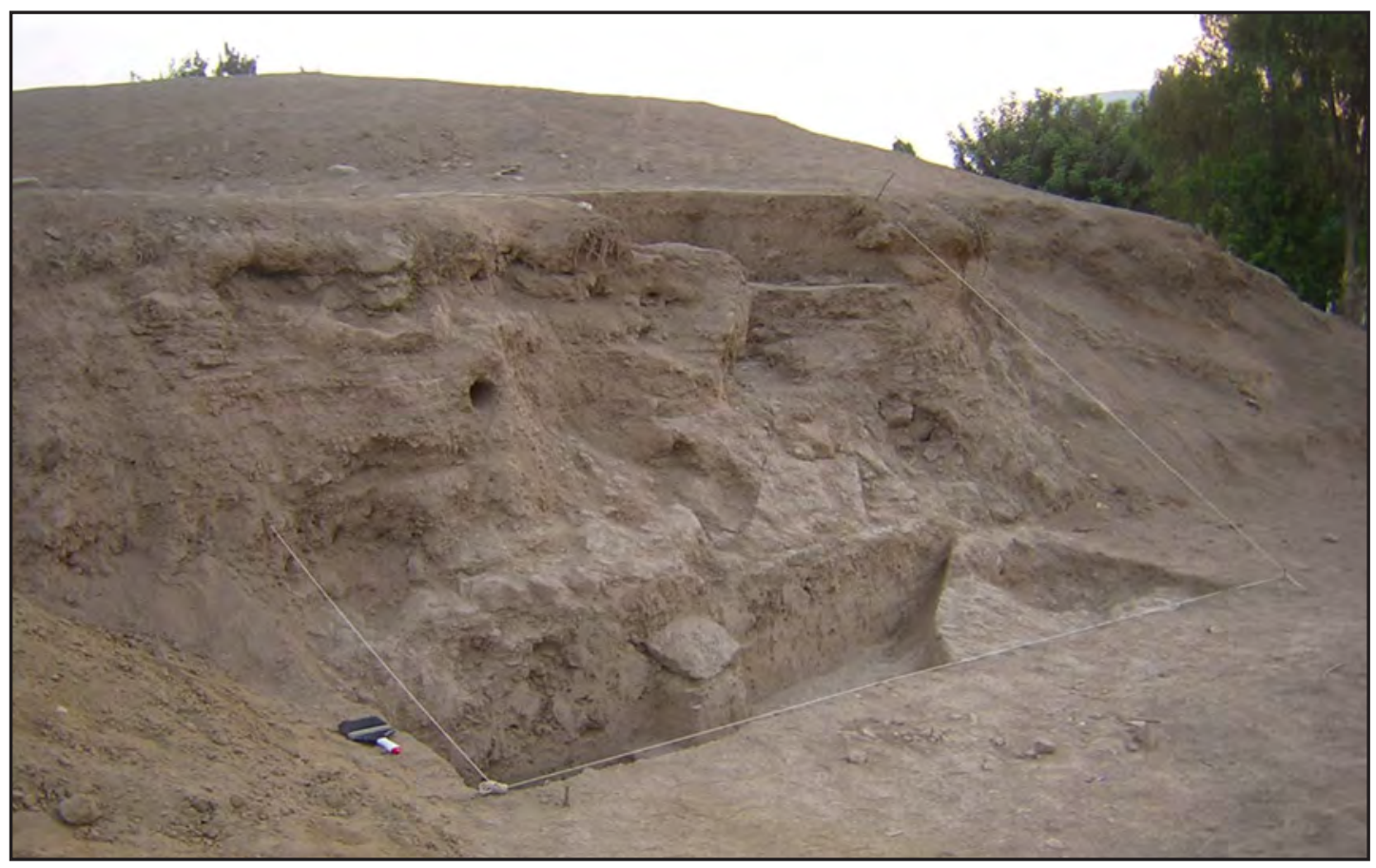

Figura 17.- Vista general desde el noreste de la unidad 4.



Figura 18.- Perfil oblicuo (mostrando dos diversos planos de corte) de la unidad 4, en el que puede verse la secuencia de pisos, rellenos y muros asociados a una secuencia de siete momentos constructivos. 
ma. La sucesión de pisos nos hacen pensar que este espacio fue usado de manera frecuente, sometiéndolo a un alto tránsito y/o actividades que hacían necesario su constante mantenimiento. El cuarto momento correspondería a la construcción del último piso de la capa 9 y los Muros 1 y 2, los cuales habrían conformado un recinto cuya esquina norte fue destruida por el corte moderno. Esta nueva configuración arquitectónica es escenario de una serie de remodelaciones representadas por los pisos registrados como capas 7 y 19. En el quinto momento, se construye el último piso de la capa 19 y el Muro 5, funcionando como un corredor con el Muro 1. Este corredor funcionó por un corto periodo de tiempo, aconteciendo dos remodelaciones (capa 20) y observándose que en la última de ellas se destruye el Muro 2 del recinto y se le sella con un nuevo piso (capa 6) sobre el cual se hallaron lajas de roca sedimentaria que po- drían haber conformado un pavimento. Este último evento constituye nuestro sexto momento constructivo, el que a su vez es totalmente sellado por las capas 4 y 5 . No obstante, resulta

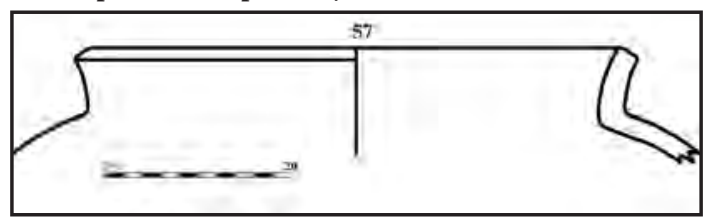

Figura 19.- Borde de un cántaro de grandes dimensiones, con borde ligeramente recto divergente $y$ bisel externo, procedente de la capa 5 de la unidad 4.

imposible determinar la configuración arquitectónica final durante este lapso pues su estado de conservación es pobrísimo debido a su carácter superficial. Acotaremos que se ha registrado desde la capa 16 a la capa 4 material cerámico del estilo Ichma Tardío (véase por ejemplo Fig. 19) $)^{8}$ así como cerámica Inka cuzqueño en superficie (Fig. 13,a). Destaca el hallazgo de un
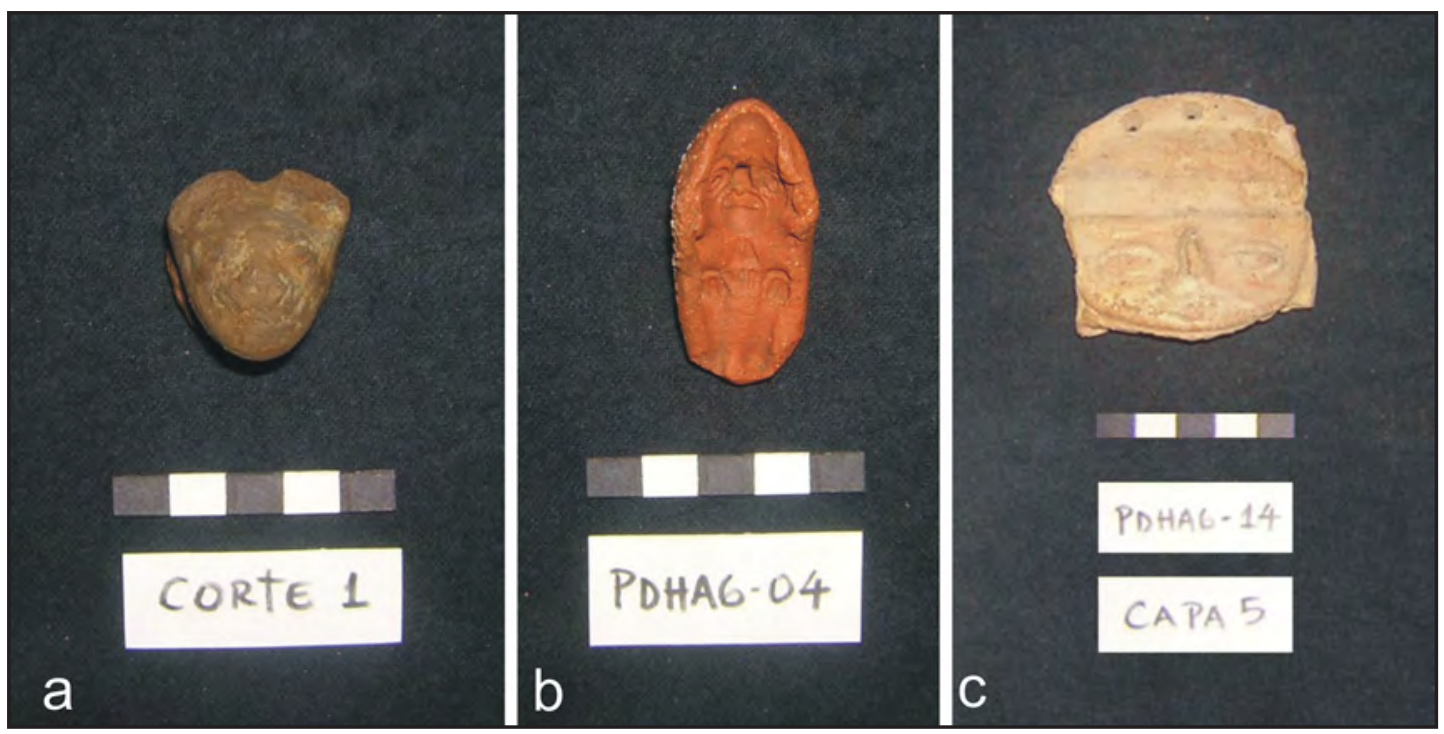

Figura 20.- Material cerámico de Aznapuquio: (a) Molde de figurina antropomorfa de estilo Inca, procedente de la capa 21 de la unidad 4, (b) aplicación representando una cabeza de felino, estilo Inca, recuperada en la capa 5 de la unidad 14, y (c) cabeza de figurina estilo Ichma, procedente de la capa 5 de la unidad 14.

8 Vasijas cerradas con labios fuertemente biselados pertenecen fundamentalmente a la fase Ychsma Tardío B de Vallejo (2004: 633). Igualmente, el borde graficado aquí, se relaciona al grupo M de Dillehay (1976: 129), quien anota que es predominante en el bajo Chillón durante el Intermedio Tardío y Horizonte Tardío. 
molde de figurina antropomorfa (Fig 20, a), característico del Horizonte Tardío. ${ }^{9}$

Por otra parte, en la unidad 8 se ha podido exponer parte de un pequeño recinto de $1.3 \mathrm{~m}$ de ancho, en cuyos paramentos se observaba una coloración blanquecina, posiblemente debida a pintura blanca. En esta unidad, las superposiciones de los elementos arquitectónicos muestran dos momentos constructivos y uno de abandono (Fig. 23). El primero lo constituye el mencionado recinto asociado a un piso (capa 6) y delimitado por los muros 1,2 y 3 . Dicho espacio es sellado con arena fina (capa 5), sobre la que se construye un piso (capa 4) que configura un segundo momento constructivo. Una gruesa acumulación de bloques de barro que se encuentra sobre todas estas estructuras corresponderían a un evento de abandono del edificio. Es interesante advertir que las estructuras que hemos podido definir se extendían, con toda seguridad, varios metros hacia el Sur. Sin embargo, actividades modernas han ocasionado la destrucción de éstas y el recorte de la extensión original del edificio.

En suma, se constata que los pisos presentan finos acabados y los muros de tapia,

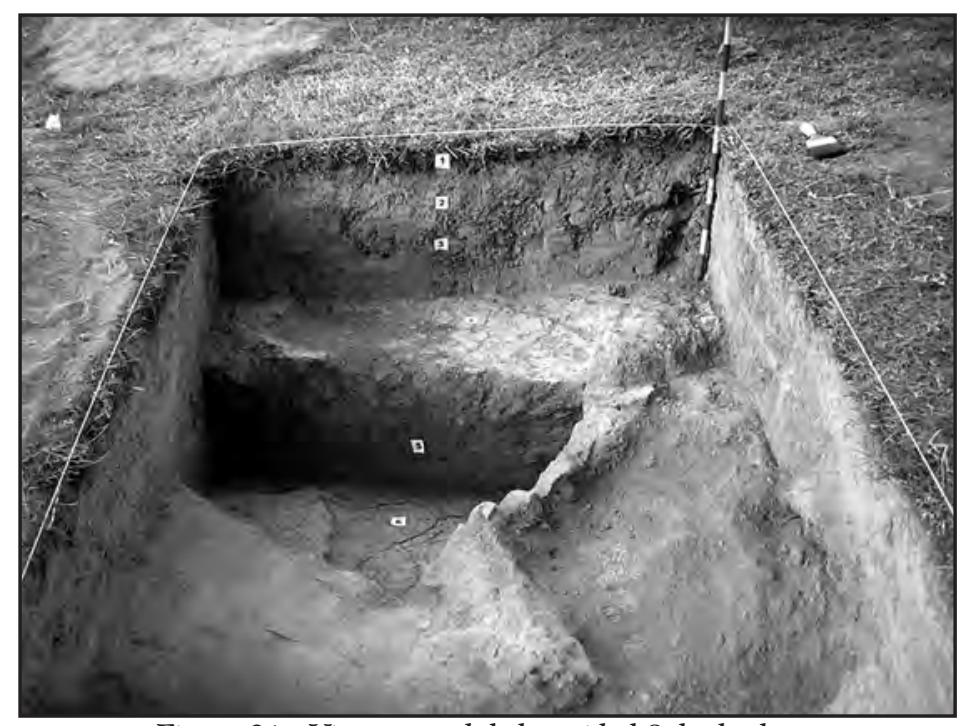

Figura 21.- Vista general de la unidad 8 desde el sur.

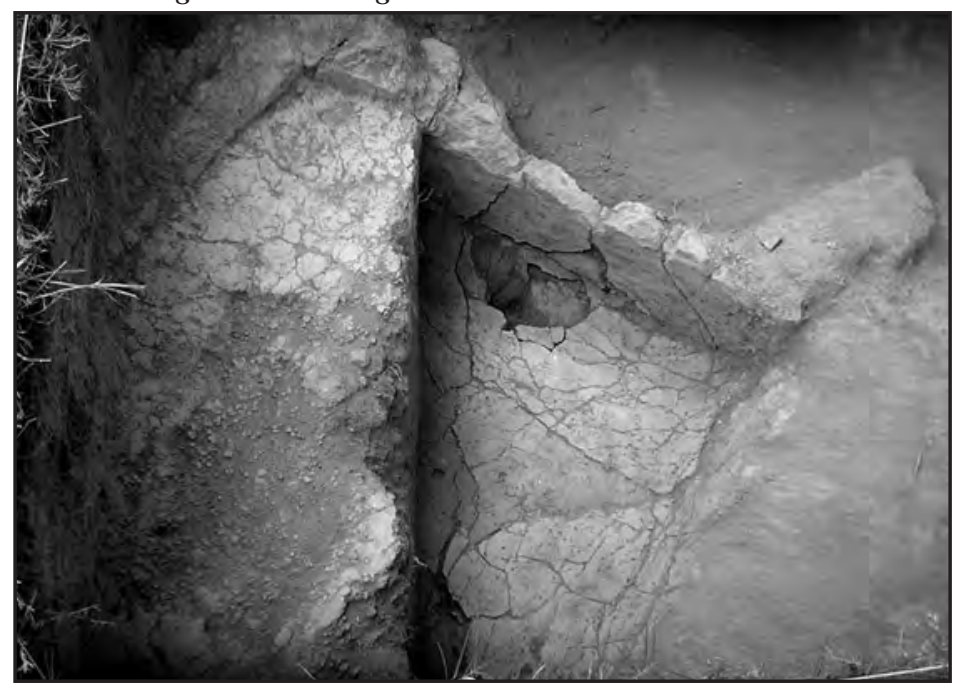

Figura 22.- Vista en planta de pisos y muros expuestos en la unidad 8. En primer término a la izquierda el piso - capa 4. En la parte baja se observa el piso - capa 6 ya la derecha un remanente de muro (Muro 2). El Muro 3 se conserva apenas como una zona con revoque que delimita a la derecha la capa 4.

muchos de ellos de considera- limpia el piso de un recinto, ble espesor, conservan enluci- previamente a su sello, ha sido dos con probable pintura blan- observado por nosotros en edica. Cabe resaltar que la carac- ficios administrativos tardíos terística de cubrir con arena del Complejo Arqueológico

9 Según Vallejo (1998) las figurinas en molde se elaboran a partir de la fase Ichma Tardío B. Compárese además el molde de Aznapuquio con aquel publicado por Feltham y Eeckhout (2004: Fig. 2, a) 


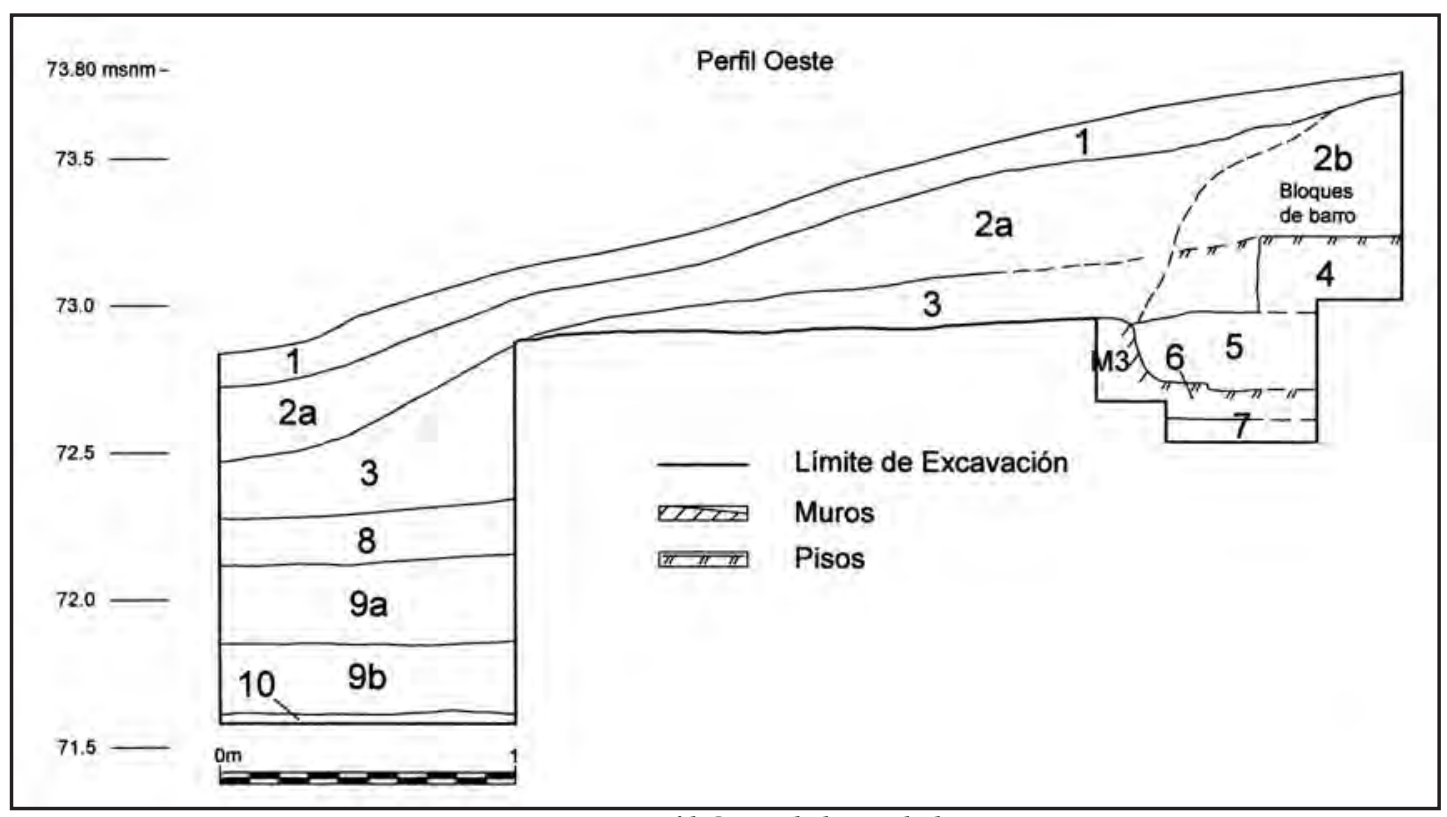

Figura 23.- Perfil Oeste de la unidad 8.

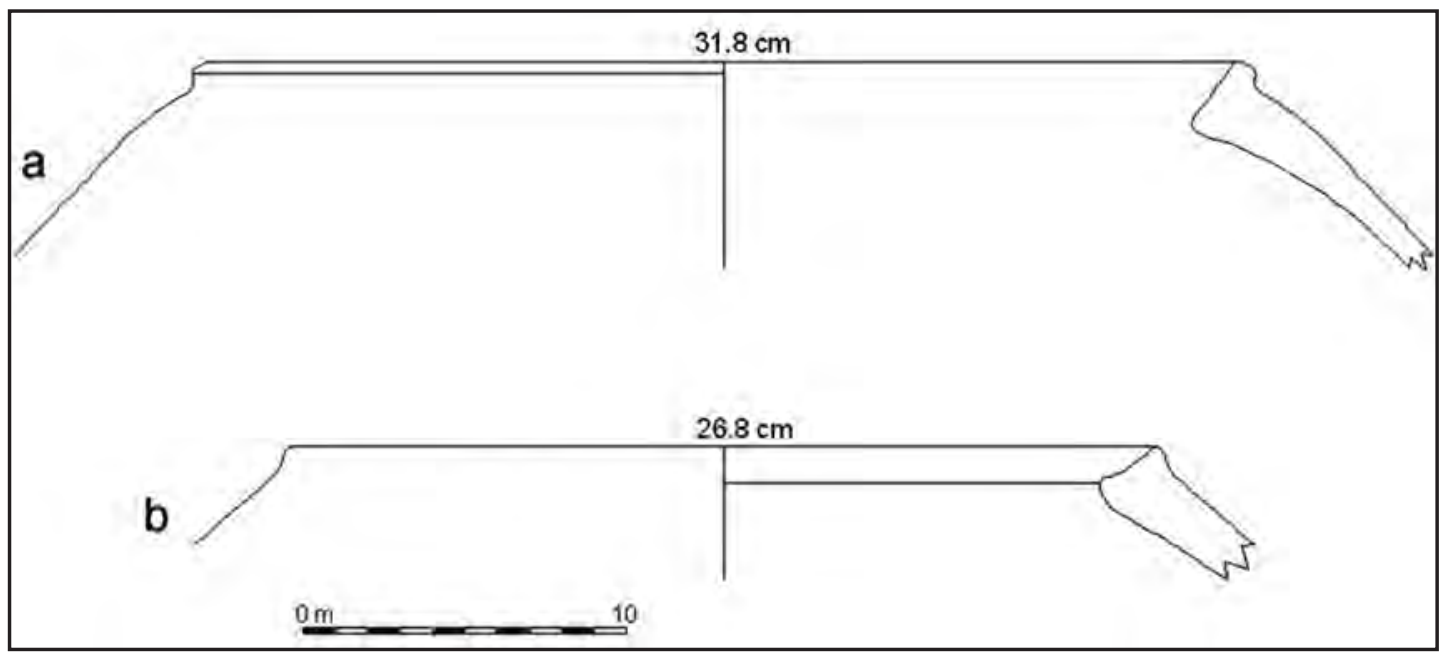

Figura 24.- Material cerámico de Aznapuquio: (a) y (b) bordes de tinajas de la capa 4 en la unidad 2, representativos de los que se hallan en el sitio. 


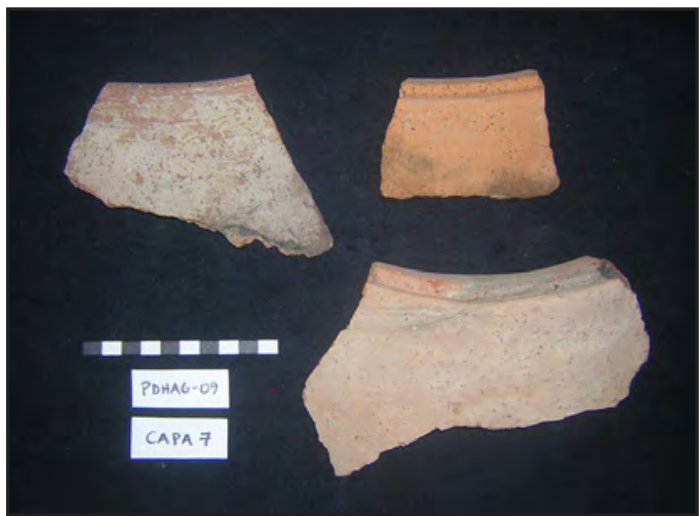

Figura 25.- Material cerámico de Aznapuquio: muestra de bordes de tinajas de la capa 7

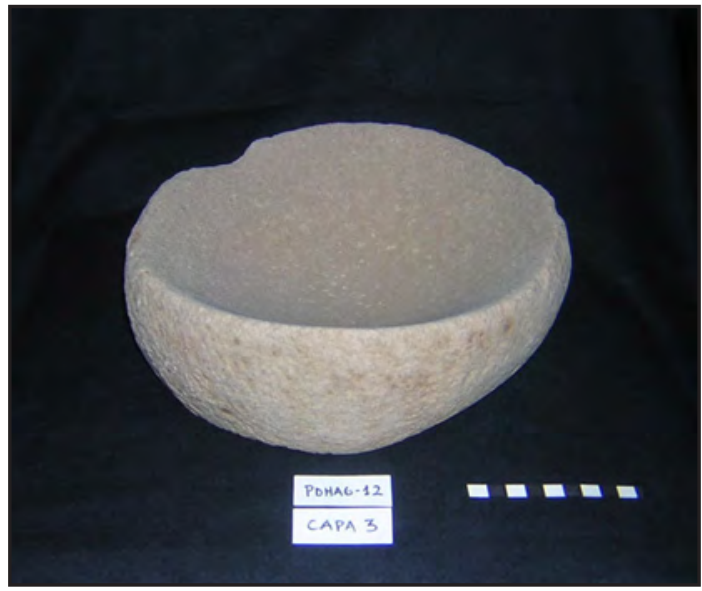

Figura 26. - Mortero de piedra procedente de la capa 3 de la unidad 12.

Maranga, como son las huacas Cruz Blanca y San Miguel; y está documentado además en la Plaza de los Peregrinos de Pachacamac y la plaza central de Huanucopampa (Shimada et al. 2004: 518).

Todos estos elementos nos sugieren la hipótesis que Huaca Aznapuquio fue un edificio de carácter administrativo, el mismo que debió haber estado asociado a actividades productivas, entre ellas probablemente la elaboración de cerámica, como se infiere por la recurrencia de restos de recocho y cerámica deformada; de almacenaje, vista la alta recurrencia de tinajas (ver por ejemplo Figs. 24 y 25); ${ }^{10}$ y a otras más bien domésticas, representadas por bolsones o lentes de desechos que han sido ubicados en varias unidades del entorno del montículo. Destaca el hallazgo de un mortero de piedra (Fig. 26) en asociación a un bolsón de desechos en la Unidad 12. Estos contextos, y quizás alguno de los lentes en el remanente de basural, podrían proceder de actividades realizadas en el interior del edificio o en algún lugar todavía indeterminado de los alrededores.

Para terminar, y como cuestión previa a la discusión sobre territorio étnico, haremos una mención general a los tipos de pasta que venimos identificando en la muestra cerámica de Aznapuquio, los cuales han sido definidas en base a su correlación con aquellas definidas por José Luis Vargas (2006) en Maranga ${ }^{11}$. Comprobamos que existe un amplio predominio de una pasta de color anaranjado rojizo, con textura laminar y temperantes de granito molido. Con esta han sido elaboradas la mayor parte de formas, incluyendo, por ejemplo, los bordes en " $T$ " aquí graficados. Los fragmentos de las figs. 13, a 20, b y 20 , c; están manufacturados con una pasta anaranjada de textura fina a media y con temperantes de cuarzo y feldespato. Como se ha visto, los dos primeros fragmentos mencionados son netamente de estilo inca cusqueño. El frag-

10 Se trata casi en el total de los casos de tinajas de borde en "T", que se originan en la fase Ichma Medio A (Díaz y Vallejo 2002a: formas 38) y perviven hasta el Horizonte Tardío.

11 Vargas ha establecido 11 grupos de pasta en una muestra de material cerámico sin contexto definido, proveniente en su mayor parte del descombramiento y limpieza de Huaca La Palma en Maranga. Dichas labores, de las que no se conserva informe técnico alguno, fueron aparentemente realizadas por José Casafranca en la década de 1960. La muestra tiene una alta proporción de cerámica diagnóstica Lima e Ichma Tardío, además de algunos fragmentos Inca cusqueño. El estudio de Vargas se ha hecho a través de análisis macroscópico directo así como por procedimientos físicos de laboratorio (Microscopía Petrográfica y Difracción de Rayos “X”). 
mento de la figura 4 está hecho en una pasta similar a la primera de las descritas, aunque es de textura poco más tosca y presenta carbonatos (posiblemente moluscos y/o "caliche" molidos) como temperantes. Ahora bien, la primera pasta mencionada corresponde al Grupo 7 de Vargas, la segunda al Grupo 1 y la última al 4. A su vez, el Grupo 7 se correlaciona a la pasta tipo "Quebrada" de Vallejo (2004:600), que, en su variedad con temperantes de granito molido, se hace más frecuente en la fase Ychsma Tardío A (Ibid. 623). Se aprecia entonces una clara correspondencia entre la cerámica de Aznapuquio y la del valle bajo del Rímac. Al mismo tiempo, son casi inexistentes en nuestra muestra, fragmentos en pasta marrón o en pasta café, asignables en este último caso al tipo cerámico que Dillehay describe escuetamente como "Collique" (1987: 421).

\section{4,2. Recursos hídricos}

Una probable falla en el valle medio del Chillón así como la naturaleza permeable del suelo en el área, hacen que en la parte baja de la cuenca aflore la napa freática originando numerosas "ciénagas" o "lagunas". La mayor profundidad (o inclinación al Norte) de la cuenca del Chillón en comparación a la del Rímac, propiciaría además el desplazamiento de las aguas subterráneas hacia el Chillón y Ancón (Ludeña 1975: 19; Daniel Chumpitaz, comunicación personal 2006), potenciando así la concentración de este tipo de fuentes a las que sería más exacto llamarlas "humedales". Estos son ecosistemas muy singulares que proporcionan sustento a aves migratorias, peces y fauna terrestre. En ellos se desarrollan también algunas especies vegetales de importancia industrial tales como el junco y la totora.

Los perfiles de excavación y el corte 1 , donde se expusieron estratos del humedal de Az- napuquio, fueron revisados con el apoyo de un edafólogo y un profesional con conocimientos de geología. De acuerdo a ellos, la alternancia de capas de arena y de limo en la estratigrafía del humedal evidencia variaciones en la fuerza del aforo, de tal manera que las capas de arena reflejan mayores volúmenes y más fuerza de ingreso de las aguas. Sin embargo no necesariamente cada una de estas capas sería correlacionable a un fenómeno tipo ENZO.

Basándonos en la estratificación (compuesta mayormente por profundos sedimentos de origen hídrico) registrada por nuestro proyecto en el entorno del montículo, podemos señalar que en un momento previo a las ocupaciones humanas más antiguas detectadas en nuestras excavaciones, el humedal de Aznapuquio se habría extendido por un área sumamente amplia. Luego de ello, el humedal se retrae sustantivamente, permitiendo ocupaciones humanas cuyas evidencias han sido registradas, como hemos visto, en la unidad 15. La cronología y los límites del humedal durante estos procesos de fluctuación, nos son desconocidos. Sin embargo, posiblemente desde fines del Horizonte Medio, el humedal creció nuevamente hasta alcanzar en el Horizonte Tardío la extensión que hemos establecido topográficamente. Por último, y muy posiblemente desde la Colonia, esta expansión se detiene y se revierte. Este deterioro de los recursos hídricos en Lima a partir de la época colonial, ha sido descrito por Agurto Calvo (1984: 29) en base a la información dada por Bernabé Cobo en el siglo XVII.

En las primeras décadas de la centuria pasada, el humedal habría empezado a ser desaguado a través de la acequia La Encantada, que se derivaba de allí para dirigirse hacia el mar. No obstante este proceso de merma, en un plano del año $1907^{12}$ muestra una extensión de hasta $4 \mathrm{Km}$. en dirección oeste por $1 \mathrm{Km}$ de longitud

12 Plano topográfico de Lima, Callao y sus alrededores (1907). Trazado y dibujado por Camilo Vallejos. Lima (?): Litografía y Tipografía Carlos Fabri. 
máxima en dirección norte. Hacia 1935, Julio C. Tello (1999: 53) aún bosqueja una extensión importante del humedal; sin embargo, pudo haber sido dibujado sólo como referencia ya que habría desaparecido pocos antes ${ }^{13}$. En las fotos aéreas de 1945, ya no se observa este ecosistema.

Por todo ello, las alusiones de Roger Ravines (1985) y Juan Paredes (2000) a Aznapuquio como un humedal de menor importancia o un simple estanque, deben entenderse en referencia a un ecosistema ya muy disminuido poco antes de su drástica desaparición. Sin embargo, hasta hace 100 años y, fundamentalmente, en tiempos prehispánicos era sumamente extenso. Se infiere entonces que humedales como el de Aznapuquio habrían sido determinantes para contar con reservas de agua ante sequías severas o eventuales conflictos con poblaciones de valle arriba, circunstancias que podían limitar el suministro de los canales de irrigación. La ocupación Inca de Aznapuquio se habría emplazado allí no sólo por ser un lugar estratégico para el acceso a recursos hídricos más permanentes que los canales derivados de los ríos, sino porque habría dotado de fuentes de arcilla para las actividades de producción alfarera y, posiblemente, fauna silvestre para manutención y gramíneas para cestería y espartería. En Aznapuquio, estas actividades se correlacionarían a la necesidad de producir mayores excedentes de producción para la administración cuzqueña.

\subsection{Territorio étnico}

No nos detendremos aquí largamente en una discusión teórica sobre los conceptos de etnicidad y territorio, ni en una evaluación del valor relativo de los indicadores arqueológicos de estos aspectos cuando se les trata individualmente ${ }^{14}$; sino que optaremos por intentar una aproximación general que propicie investigaciones en esta temática. Con este propósito, examinaremos e interrelacionaremos las evidencias sobre cerámica, patrones de asentamiento, patrones funerarios y otros datos que, desde el caso de Aznapuquio, permitan individualizar una etnía y su territorio.

Los datos de Aznapuquio corroboran que las cuencas bajas del Chillón y el Rímac compartían el estilo cerámico Ichma. Al mismo tiempo, una revisión de las investigaciones en la zona nos permite constatar que no existe ningún estilo, distinto al Ichma, que pueda correlacionarse con seguridad al territorio Colli tal como éste es definido por la etnohistoria. ${ }^{15}$ Ello podría ser explicado de acuerdo al concepto de la Provincia Inca de Pachacamac (Parssinen 2003: 300 y ss., Cornejo 2000), según el cual el Tahuantinsuyu habría incorporado al bajo Chillón a la circunscripción Ichma, como el hunu de Carabaillo mencionado por Bernabé Cobo (Cornejo 2000: passim). Sin embargo, esta explicación, en un plano teórico, entraña un debatible supuesto de relación necesaria entre estilo de cerámica y etnía (cuando es sabido que un mismo estilo puede ser compartido por grupos étnicos distintos) , mientras que, por el lado de las evidencias materiales, debería sustentarse en datos concretos sobre una cronología Horizonte Tardío para la cerámica Ichma del Chillón, lo cual resulta improbable en tanto parece existir una correspon-

\footnotetext{
13 En el Plano Lima y sus alrededores (1932), levantado por el Servicio Geográfico del Ejército, el área donde se hallaba el humedal se encuentra parcelada por campos de cultivo.

14 Para una discusión teórica sobre etnicidad e indicadores arqueológicos, remitimos al lector al artículo de Kaulicke (2004). Para una evaluación sobre la arquitectura y la cerámica como indicadores de identidad véase Makowski 2002, y Makowski y Vega Centeno 2004.

15 Los grupos de cerámica definidos por Dillehay (1976) como propios del Chillón bajo y medio, también están presentes en Chancay, Rímac y Lurín (Silva, 1996: 391 - 392), correspondiendo en estos dos últimos casos a formas Ichma.
} 
dencia esencial entre el estilo Ichma del Rímac y el del Chillón desde el Intermedio Tardío.

A nuestro modo de ver, una correlación entre arquitectura, patrones funerarios y cerámica podría llevarnos a esbozar con mayor confiabilidad territorios étnicos. Desafortunadamente, es muy desigual la información sobre estos indicadores en el bajo Chillón es muy desigual e incompleta por lo que nuestras apreciaciones deberán tener necesariamente carácter de hipótesis.

Así, la información sobre contextos funerarios del valle bajo del Chillón, es prácticamente inexistente y se tienen sólo algunas investigaciones que destacan los hallazgos de cerámica Chancay (por ejemplo en El Palmo y Pampa de Animas, Stumer 1954). Ello constituye un lamentable vacío en la investigación, pues a nuestro entender los patrones funerarios tienen una especial relevancia como indicadores arqueológicos de diferencias étnicas incluso poco evidentes en la arquitectura ${ }^{16}$.

Si bien la muestra de arquitectura registrada por nuestro proyecto es demasiado pequeña para ensayar una tipología comparativa, puede señalarse que la morfología y disposición espacial de los montículos del llamado Complejo Arqueológico Aznapuquio guarda mayor correspondencia con los "conglomerados de montículos" (Silva 1992: 397), propios de la cuenca baja y media del Chillón desde el Intermedio Tardío, y no con los grandes edificios en torno a una plaza, característicos de la cuenca inferior del Rímac en sitios como Maranga y Mateo Salado. No obstante, es probable que los conjuntos con canchones y recintos en tapia ${ }^{17}$, como son el Palacio de Oquendo, Cerro Respiro ${ }^{18}$ y Tambo Inca, hayan cumplido funciones análogas a sus pares mayores del Rímac, como el Recinto Amurallado de Maranga, sirviendo unos y otros como residencias y centros administrativos reservados a la élite cusqueña. A todo esto, hay que notar que las pirámides con rampa, el tipo de edificación Ichma más emblemático hasta inclusive el Horizonte Tardío (Díaz y Vallejo 2002b: 360), son evidencia negativa en el Chillón ${ }^{19}$.

La vinculación de Aznapuquio a los patrones arquitectónicos del bajo Chillón sugiere la hipótesis de que el sitio pudo haber sido construido por pobladores locales movilizados y asentados allí por los incas para ser dedicados a la producción de bienes para el imperio. En relación a ello, y como explicáramos antes, el establecimiento de Aznapuquio a la vera de un camino permitió interconectarlo directamente con asentamientos estratégicos del Tahuantinsuyu, como Tambo Inca, respondiendo a la necesidad de articularlo con éstos e incorporarlo a la esfera de distribución económica en la costa central. Es comprensible que una de las principales funciones de Aznapquio fuese la manufac-

16 En el valle bajo del Rímac, Daniel Guerrero (2004: 163), y Luisa Díaz y Francisco Vallejo (2005: 302) han detectado diferencias en los contextos funerarios de sitios contemporáneos del valle del Rímac, las cuales reflejarían diversidades culturales intrarregionales. Puede verse además Cornejo 2002 y 2004 para estudios de caso referidos a cementerios multiétnico de artesanos mitimaes. Por otra parte, debemos mencionar que, aún cuando se trata de una zona fuera del ámbito espacial estricto de nuestra investigación, queda todavía pendiente la identificación de rasgos culturales Ichma en los contextos funerarios de Ancón. En el trabajo de Ravines y Stothert (1976: vasija Sp. An 05/ 76) puede apreciarse una olla Ichma Tardío.

17 Reconocidas algunas de ellas por Villar Córdova con el nombre de "Ciudades Fortificadas" (1982: 189). Llamadas también "Villas" por Patterson y Lanning (1964: 117).1

18 Las "Ciudadelas" de Tello (1999: 51, inter alia)

19 Una probable excepción sería Huaca Pro, donde, entre la escasa arquitectura visible, se aprecian plataformas que van ganado altura y accesos indirectos hacia la plataforma inferior, rasgos que recuerdan a Huaca La Palma de Maranga. 
tura alfarera, pues esta se intensificó a lo largo del Horizonte Tardío con la finalidad de maximizar el almacenaje y cumplir con los principios de reciprocidad en un imperio multiétnico cada vez más extenso.

En resumen, la banda derecha del bajo Chillón se ha caracterizado arqueológicamente por contar con una mayor presencia de elementos culturales ligados a la Costa nor-central (entre estos, una manifiesta recurrencia del estilo Chancay, por ejemplo), en comparación con la margen opuesta (Marcus y Silva 1988: 43). Al mismo tiempo los "conglomerados de montículos" responden a un patrón de asentamiento claramente distinto al del Rímac y Lurín, y se distribuyen consistentemente en las terrazas aluviales entre Marquez y La Pampilla, en sentido horizontal, y entre el litoral y Santa Rosa de Quives, en sentido vertical (Silva 1992: 392). Sin embargo se constata una alta concentración de éstos en la margen izquierda, como ocurre en el Complejo Arqueológico Oquendo. Por otra parte, Villar Córdova ha hecho notar que las arquitectura costeña en tapia se presenta hasta la altura de Zapán, en la margen izquierda del Chillón, y Huarabí Bajo, en la margen opuesta (1982: 173 y 174). Esta última localidad es también el límite oriental de la distribución de material cerámico Chancay, pues valle arriba se presenta sólo aisladamente hasta Quivi Vieja (Dillehay 1976: 184). Villar Córdova (1982: 188) ha destacado además la presencia de lo que considera un importante sector militar en la margen izquierda del Chillón, que se iniciaba con una muralla de tapia que cerraba el acceso por Huanchipuquio, mientras que Trapiche y Macas cerraban el acceso desde la quebrada Huachoc y Socos. ${ }^{20}$ Valga señalar que la quebrada Huachoc es un paso natural hacia el valle medio de Chancay. Estos indicios hacen presumir la existencia de una sociedad que ocupó fundamentalmente la banda izquierda del bajo Chillón, mientras que la franja entre Huanchipuquio y Quibi, es decir la chaupiyunga, se manifiesta como una suerte de zona cultural intermedia sujeta a influencias tanto de la costa como de la sierra, muy posiblemente por su capacidad productiva de coca. Al mismo tiempo, Carabai$1 \mathrm{l}^{21}$ y los demás sitios mencionados para la ribera opuesta aparecen fuertemente vinculados a Chancay. Dillehay ha llegado a una conclusión similar señalando que los colli se asentaron en la margen sur mientras que los carabaillo lo hicieron en la opuesta (Dillehay 1976: 202). Aunque, siguiendo el razonamiento de Dillehay, el río Chillón aparece como una frontera natural de dos grandes grupos étnicos susceptibles de ser distinguidos por medios arqueológicos, los límites territoriales no parecen ser rígidos sino permeables, permitiendo asentamientos que serían producto de una territorialidad salpicada. Ellos explicaría tentativamente, por ejemplo, porqué hay "conglomerados de montículos" en la banda derecha del Chillón.

20 Villar acota que las estructuras militares de la margen izquierda formaban parte de un sistema de defensa que se "escalonaba hasta la gran fortaleza de "Kollique", en una extensión de 27 kilómetros, a lo largo del tramo o camino hacia el Norte" (Ibid.)

${ }_{21}$ Carabaillo es resaltado por Bernabé Cobo no sólo como uno de los tres hunus en que los Inca dividieron Lima, sino como una nación con una lengua distinta a la que se hablaba al sur del río Chillón (1956 [1653]: 301). Rostworowski duda sobre la veracidad de esta última apreciación pues supone, basándose en los nombres de las pachacas Colli, que éstos hablaban quechua al igual que los Ichma (2004: 43 - 44). De acuerdo a lo explicado por nosotros hasta aquí, creemos que la aseveración de Cobo no debería ser tan fácilmente descartada (ver Patterson y Lanning 1964: 116 -7, Silva 1992: 397-398). Por su lado, Dillehay ha propuesto que el sitio arqueológico de Carabayllo correspondería al centro de poder local mencionado en la documentación colonial (1976: 202). 


\section{Síntesis final y perspectivas de estudio.}

Los datos arqueológicos obtenidos por el Proyecto de Delimitación de Huaca Aznapuquio, indican que la ocupación intensiva del área de Aznapuquio y la subsiguiente construcción de arquitectura en el sitio, corresponden al Horizonte Tardío, habiéndose hallado sólo evidencias aisladas y poco definidas de periodos cronológicos previos. Nuestras investigaciones corroboran y amplían así los resultados obtenidos por Hugo Ludeña (1975). El establecimiento de un probable edificio administrativo del Horizonte Tardío en las orillas de un humedal, junto a otras construcciones prehispánicas, hoy desaparecidas y que fueron presuntamente contemporáneas, estaría motivado por la necesidad de obtener mayores recursos para la economía imperial del Tahuantinsuyu. Las evidencias de actividades domésticas (basural de los cortes 1 y 2) y la cuidadosa elaboración de la arquitectura expuesta, sugieren que si bien la manufactura de cerámica fue una de las actividades protagónicas que se desarrollaron en Aznapuquio, su función no se limitó a las que habría cumplido un taller sino principalmente al control de la producción, a cargo de trabajadores residentes, y a su distribución ulterior. Futuros trabajos deberán definir la existencia de áreas domésticas asociadas, además de corroborar por métodos físicos de laboratorio si las fuentes de arcilla utilizadas para la cerámica local son en efecto los bancos del humedal y, consecutivamente, si los alfares de otros sitios de la esfera Ichma bajo el dominio Inca, son exactamente los mismos de Aznapuquio, como parece serlo por su estrecha correlación con cerámica tardía de Maranga (Vargas 2006). De ser positivos los resultados de este último aspecto se comprobaría que el bajo Chillón se consolidó como un centro productor de cerámica Ichma e Inca en el Horizonte Tardío. En cuanto a corología, puede señalarse que la morfología y disposición espacial de los montículos del llamado Complejo Arqueológico Aznapuquio guarda mayor correspondencia con los conglomerados de montículos, propios del bajo Chillón, que con los grandes edificios en torno a una plaza, característicos de la cuenca inferior del Rímac. En este panorama parece ser que los conjuntos con canchones y recintos de tapia del bajo Chillón habrían cumplido funciones análogas a los conjuntos amurallados del Rímac, estando ambos reservados a las élites locales y cusqueñas. Siendo la arquitectura un indicador fundamental de etnicidad, se propone como hipótesis que poblaciones locales son movilizadas, construyen y se asientan en nuevos centros productivos al servicio de los incas, manufacturando un tipo de cerámica que, muy probablemente, comparten con el Rímac y el Lurín desde el Intermedio Tardío. La distribución de estos conjuntos arquitectónicos del bajo Chillón coincide a grandes rasgos con la extensión territorial que se postula para los Colli desde la etnohistoria.

\section{Agradecimientos}

Queremos expresar nuestro agradecimiento al edafólogo Edwin Alejandro Berrospi y al Sr. Juan Roldán Pajuelo por asistir al campo y analizar la estratificación asociada al humedal. Igualmente, agradecemos a José Luis Vargas Villalta por su disposición para apoyarnos en la revisión del material cerámico de Aznapuquio y constatar su correlación con la muestra de Maranga. Nuestro reconocimiento también para Katty Huamán y Enrique Bellido, bachilleres de arqueología de la Universidad Nacional Mayor de San Marcos, y para Marco Valderrama, estudiante de arqueología de la misma universidad, quienes desinteresadamente nos ayudaron como voluntarios durante nuestras excavaciones. 


\section{Bibliografía}

Agurto, Santiago

1984 Lima Prehispánica. Lima: Municipalidad de Lima Metropolitana - FINAMPRO.

Astuhuamán, César

2006 El concepto de provincia inca. Arqueología y Sociedad 17: 273 - 292.

Ávila, Francisco de

1966 [1598?] Dioses y Hombres de Huarochirí. Narración quechua. Lima: Museo Nacional de Historia e Instituto de Estudios Peruanos.

Bonavia, Duccio

1966 Sitios Arqueológicos del Perú (Primera Parte). Arqueológicas 9.

Carrión, Lucénida y Pedro Espinoza

2007a Arquitectura, cronología y función en la Muralla 55E del Complejo Arqueológico Maranga. Cuaderno de Investigaciones del Museo de Sitio "Ernst W. Middendorf" 1: 33 - 66.

2007b Investigaciones en la Huaca San Miguel, Complejo Arqueológico Maranga. Cuaderno de Investigaciones del Museo de Sitio "Ernst W. Middendorf" 1: $67-115$.

Cobo, Bernabé

1956 [1935] Fundación de Lima. Biblioteca de Autores Españoles desde la Formación del Lenguaje hasta nuestros días 92: 277 - 460. Madrid: Ediciones Atlas.

Cornejo, Miguel

1999 An Archaeological Analysis of an Inka Province: Pachacamac and the Ischma Nation of the Central Coast of Peru. A thesis submitted for the Degree of Doctor of Philosophy in the Department of Archaeology and Anthropology of the Australian National University. Canberra: manuscrito.

2000 La Nación Ischma y la Provincia Inka de Pachacamac. Arqueológicas 24: 149-173.

2002 Sacerdotes y tejedores en la provincia Inka de Pachacamac. Boletín de Arqueología PUPC 6: 171 - 204.

2004 Pachacamac y el Canal de Guatca en el bajo Rímac. Bulletin de l'Institut Français d'Études Andines 33 (3): 783 $-814$.

Díaz, Luisa y Francisco Vallejo

2002a Identificación de Contextos Ichma en Armatambo. Arqueología y Sociedad 14: $47-75$.

2002b Armatambo y el dominio Incaico en el valle de Lima. Boletín de Arqueología PUPC 6: 355 - 374.

2005 Clasificación del patrón funerario ychsma identificado en Armatambo y La Rinconada Alta. Corriente Arqueológica 1: $223-322$.

Dillehay, Tom

1976 Competition and Cooperation in a Prehispanic Multi-ethnic System in the Central Andes. Ph. D. dissertation. Department of Anthropology, University of Texas. Austin: manuscrito.

1987 Estrategias Políticas y Económicas de las Etnias Locales del Valle del Chillón durante el Período Prehispánico. Revista Andina 2 (V): 407-456.

Dominguez, Nicanor

1988 Aguas y Legislación en los Valles de Lima, el Repartimiento de 1617. Boletín del Instituto Riva Agüero 15: 119. 154.

Espinoza, Pedro

2006 Informe Final del Proyecto de Delimitación de Huaca Aznapuquio, Distrito de Los Olivos - Lima. Presentado al Instituto Nacional de Cultura. Lima: manuscrito.

Feltham, Jane y Peter Eeckouth

2004 Hacia una definición del estilo Ychs- 
ma: aportes preliminares sobre la cerámica Ychsma Tardía de la Pirámide III de Pachacamac. Bulletin de l'Institut Français d'Études Andines 33 (3): 643 $-679$.

Guerrero, Daniel

2004 Cronología cerámica y patrones funerarios del valle del Rímac: una aproximación a los periodos tardíos. En Puruchuco y la Sociedad de Lima: Un homenaje a Arturo Jiménez Borja; editado por Luis Felipe Villacorta Ostolaza, pp. 157 - 177. Lima: CONCYTEC.

Gunther, Juan

1983 Planos de Lima 1613-1983. Lima: Municipalidad de Lima Metropolitana.

Kaulicke, Peter

1997 Contextos funerarios de Ancón. Esbozo de una síntesis análítica. Lima: Pontificia Universidad católica del Perú.

2004 Identidad, etnicidad e imperios: algunas reflexiones finales. Boletín de Arqueología PUPC 8: 325 - 357.

Ludeña, Hugo

1975 Secuencia Cronológica y Cultural del Valle del Chillón. Tesis para optar por el grado de Doctor en la Especialidad de Arqueología, UNMSM. Lima: manuscrito.

Luján, Karen; Alberto Tapia y Alan Ríos

2004 RESUMEN: Reconocimiento del Estado Actual de los Sitios Arqueológicos del Distrito de Los Olivos, Resultados Preliminares. Informe interno del Proyecto Arqueológico Los Olivos, Noviembre 2004. Lima: manuscrito.

Makowski, Krysztof

2002 Arquitectura, estilo e identidad en el Horizonte Tardío: el sitio de Pueblo Viejo-Pucará, valle del Lurín. Boletín de Arqueología PUPC 6: 137 - 170.

Makowski, Krysztof y Milena Vega-Centeno
2004 Estilos regionales en la Costa Central en el Horizonte Tardío. Una aproximación desde el valle del Lurín. Bulletin de l'Institut Français d'Études Andines 33 (3): 681 - 714.

Marcus, Joyce y Jorge Silva

1988 Los Cocales del Valle del Chillón. Evidencia Arqueológica y Contexto Ecológico. Studies in Latin America Etnohistory and Archaeology 21 (IV): $1-52$.

Menzel, Dorothy

1968 La Cultura Huari. Lima: Compañía de Seguros y Reaseguros Peruano Suiza.

Paredes, Juan

2000 La Cultura Lima en el Valle bajo del río Chillón. Arqueología y Sociedad 13: 133-158.

Patterson, Thomas C. y Edward Lanning

1964 Changing settlement patterns on the Central Peruvian coast. Nawpa Pacha 2: $113-123$.

Parssinen, Martti

2003 Tawantinsuyu. El estado Inca y su organización política. Lima: Instituto Francés de Estudios Andinos, Pontificia Universidad Católica del Perú, Embajada de Finlandia.

Ravines, Rogger

1981 Prácticas funerarias en Ancón (Segunda parte). Revista del Museo Nacional XLV: 89 - 166.

1985 Inventario de los Monumentos Arqueológicos del Perú (Lima Metropolitana). Primera aproximación. Lima: INC - Municipalidad de Lima Metropolitana.

Ravines, Rogger y Karen Stothert

1981 Un entierro común del Horizonte Tardío en la costa central del Perú. Revista del Museo Nacional XLII: 153 $-205$. 
Rostworowski, María

2004 Costa Peruana Prehispánica. Obras Completas III. Lima: Instituto de Estudios Peruanos.

Shimada, Izumi, Rafael Segura, María Rostworowski e Hirokatsu Watanabe

2004 Una nueva evaluación de la Plaza de los Peregrinos de Pachacamac: aportes de la primera campaña 2003 del Proyecto Arqueológico Pachacamac. Bulletin de l'Institut Français d'Études Andines 33 (3): 507 - 538.

Silva, Jorge

1992 Patrones de Asentamiento en el Valle del Chillón. En Estudios de Arqueología Peruana, editado por Duccio Bonavía, pp.393- 415. Lima: FOMCIENCIAS.

1996 Prehistoric Settlement Patterns in the Chillon River Valley. Ph. D. dissertation, Department of Anthropology, University of Michigan, Ann Arbor. Michigan: manuscrito.

Stumer, Louis

1954 The Chillon Valley of Peru: Excavation and Reconnaissance, 1952 - 1053, Part 2. Archaeology 7 (4): 222 $-228$.

Tello, Julio

1999 Arqueología del Valle de Lima. Cuadernos de Investigación del Archivo Tello 1. Lima: Museo de Arqueología y Antropología de la UNMSM.

Vallejo, Francisco

1998 Secuencia cronológica en base a la cerámica Ichma. Separata del Primer Coloquio de Arqueología del Valle del Rímac durante el Intermedio Tardío. INC - Museo de Puruchuco, Lima.

2004 El estilo Ychsma: características generales, secuencia y distribución geográfica. Bulletin de l'Institut Français d'Études Andines 33 (3): 595 - 642.
Vargas, José

2006 Estudio de material cerámico del Complejo Arqueológico de Maranga. Informe manuscrito presentado al Curso de Prácticas Pre-profesionales de la Escuela Académico Profesional de Arqueología, UNMSM. Lima. Manuscrito

Villar, Pedro

1982 [1935] Arqueología del Departamento de Lima. Lima: Ediciones Atusparia. 